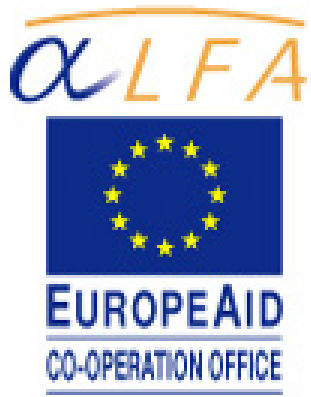

\title{
DIRECTORY OF SCHOOLS OF LIBRARIANSHIP AND INFORMATION SCIENCES IN LATIN AMERICA - PAST AND PRESENT
}

\section{I an M. Johnson}

Professor and Associate Dean, Aberdeen Business School, The Robert Gordon University, Garthdee Road, Aberdeen AB10 7QE, Great Britain (i.m.johnson@rgu.ac.uk)

\section{Abstract}

The paper introduces a directory of Schools of Librarianship and Information Sciences in Latin America. This was based on existing printed directories, and an extensive web search in January 2007. An appended directory lists 127 instituions in the region that have or are currently offering courses in the subject, of which 100 appear to be active.

\section{Introduction}

One indicator of the changes affecting the LIS profession in Latin America is the apparently steady increase in the number of universities where LIS is taught. Communication within the region, and even within its larger countries, is poor. This not only affects awareness of the existence of relevant courses, but also hinders the pace of development.

\section{Previous directories}

Previously published directories of Schools of Librarianship and Information Studies in Latin America have been both incomplete and inconsistent in their coverage. The first known guides to Schools and courses appear to be those compiled on behalf of the Union Panamericana in the 1950s [1]. UNESCO has since supported the publication of several international directories of Schools of Librarianship. The first, published in 1972, identified only 34 Schools in 11 of the 20 Spanish and Portuguese speaking states in the region, although many of these were no more than training centres established by major libraries [2]. In 1985, in a directory compiled by IFLA's Education and Training Section with 
UNESCO support, it was recorded that there 71 Schools in 17 countries [3], but the compilers of a later edition of the same directory secured reports from only 47 Schools, although, again, only 3 countries were not represented [4]. To date, IFLA's Education and Training Section has, for various reasons, been unsuccessful in its efforts to compile a new edition of its global directory. A study undertaken by this author in $1997 / 98$ estimated that the total number of Schools still in existence in the region amounted to no more than 58. 9 countries appeared then to have then not yet established any School teaching the discipline [5]. However, more recent studies identified that the discipline has been taught in over 80 universities in 16 countries in the region [6]. The seemingly continual changes, which have led one commentatator to note that obtaining reliable data about them is problematic $[7,8]$, inhibit analysis of their current sufficiency and relevance.

\section{REVI STAS}

The REVISTAS project was undertaken by an international partnership with support from the European Commission's ALFA programme (América Latina Formación Académica). It was intended to identify professional journals published in the region with a view to ensuring their wider availability through digitisation and thus contribute to professional education and development. The principal users of the journals were expected to be the Schools and Departments teaching and undertaking research in the discipline, and the compilation of this list of Schools and Departments was undertaken so that the information about available journals could be distributed to them.

The preparation of a current list of Schools was complicated by the changing nature of higher education in general, and this investigation has been useful in resolving some of the consequential problems. In some cases, courses have simply been transferred from a library to an institution of higher education. In other cases, institutions' status and names have changed. Similarly, this revised listing resolves some confusion that may have arisen because of different local conventions in presenting addresses (for correspondence and/or visiting), or because addresses were incomplete or incorrectly transcribed in earlier printed directories.

\section{Methodology}

Entries from the 3 printed directories that had been prepared with UNESCO support $[9,10,11]$ were compiled as an initial basis for web searches. The entries in these printed directories have been supplemented or updated by searching the lists of Schools on several Web sites:

- UNESCO Libraries portal - http://www.unesco.org/cgibin/webworld/portal_bib2/cgi/page.cgi?g=Training\%2FInstitutions\%2FLatin_ America\%2Findex.shtml; $d=1$

- UNESCO Archives portal http://www.unesco.org/webworld/portal_archives/pages/index.shtml

- INFOLAC - UNESCO Programa para la Sociedad de la Información en América Latina y El Caribe - http://infolac.ucol.mx/directorio/escuelas.html

- World List of Departments and Schools of Information Studies, Information Management, Information Systems, etc. http://informationr.net/wl/wlist7.html 
- Universia, a portal linking 650 universities, with national nodes in 10 countries (Argentina, Brasil, Colombia, Chile, España, México, Perú, Portugal, Puerto Rico, and Venezuela) - http://www.universia.net/

- EDIBCIC - Asociación de Educacion e Investigacion en Bibliotecología, Archivología, Ciencias de la Información y Documentación de Iberoamérica y el Caribe - http://www.edibcic.org/index.htm

- Grupo Baratz - Servicios de Teledocumentación - Centro de servicios y recursos para bibliotecas y bibliotecari@s: Universidades: dónde estudiar http://www.absysnet.com/recursos/recuniversidades.html\#Iberoamerica

- Centros de Recursos para el Aprendizaje (Página creada para los Bibliotecarios Escolares del Mundo Hispano, Enero 2005): Escuelas y Departamentos de Bibliotecologia http://www.geocities.com/crachilecl/asociac.htm

- ABECIN - Associaçao Brasileira de Ciencia da Informaçao http://www.abecin.org.br/Escolasal.htm

- Conselho Federal de Biblioteconomia (Brasil) http://www.cfb.org.br/html/instituicoes.asp

- Conselhos Regionais de Biblioteconomia (Brasil) http://www.cfb.org.br/html/links_regionais.asp

The searches were undertaken in January 2007. It was evident that many of these web-based directories had not been updated recently, and none were comprehensive. Nonetheless, most of the new entries in the list appended to this note originate from the web sites. In addition, a small number of courses were initially identified from the institutional attributions of authors of journal articles on professional education in the region, or by serendipity.

Web sites in Latin American Universities and libraries are at various stages of development. Some websites were under reconstruction at the time they were investigated. Aesthetics are frequently more impressive than functionality. Structures are variable, and a wide variety of terminology is used is used to headline the internal structure of web sites, and information is presented in greater or lesser detail using an equally wide variety of practices. Navigation is frequently poor - a high 'click' count may be needed to find the right page. The lack of planned web site development is further reflected in broken links because changes have been introduced without links from abandoned URLs.

Some institutions do not appear to support individual web pages for Faculties, Schools, Departments, or in some case courses. Some have consequently set up their own web site. Where the organisational entities do have web pages, in many cases there is no link from them to details of courses, staff, publications, etc. Similarly, in many cases there are no links from course web pages to the relevant part of the institution responsible for the course's management and delivery. There is consequently some inconsistency in this list, as it has not always proved possible to identify the name of the School, Department or Faculty hosting a course, whereas in some instances a greater degree of detail is provided, occasionally simply to ensure that correspondence reaches the correct part of the institution if this list is used for addressing purposes. In the appended directory, some URLs may need truncating to their root to access a page from which it is necessary to navigate through the site to the relevant page(s). 
Some URLS are presented only at the institutional level because the detail of departmental or course page locators is not in the public domain. The inclusion of a URL in the appended list, however, simply confirms that the institution still exists, although it may not have been possible to find a page for a relevant department or course. Without direct evidence from a web site, it is not possible to confirm definitely that the institution concerned still offers a relevant course. This Directory includes entries that appeared in previously published directories even though it has not been possible, through a web search, to locate the institution concerned or a relevant current course in an institution. The omission of a URL from an entry simply indicates that it was not possible to find a web site that corresponds to the institution in previous printed or online directories. The results of searches in some institutions' web sites do, however, suggest that some relevant courses have been withdrawn, temporarily or permanently.

\section{Results}

These investigations suggest that the higher education institutions in even the smallest countries in the region have at some time addressed the need to educate information professionals. The searches revealed that a total of 127 institutions appear to have offered courses in librarianship and information sciences in the Spanish and Portuguese speaking countries in the region or are currently offering them, of which 49 had not appeared in the 3 printed directories that were examined at the start of the search. Sufficient evidence could not be found to confirm that 27 of the institutions that had been listed in the printed directories or on web sites were currently offering courses. Nonetheless, the total number of institutions whose web sites are currently offering courses (100, including one was identified though a personal communication with a Fulbright scholar who was involved in plans to establish a new course) is significantly greater than had previously been known for certain. Interestingly, in proportion to the region's population, this is about the same as the number of ALA accredited SLIS in the USA, although it is noticeable that there distribution between countries is uneven. Only one country does not appear currently to support a course in the discipline, but many of the larger urban areas in some of the least developed or geographically large countries have no local access to education in the field. This suggests that there may be a small but significant market for Spanish-language distance education providers at both undergraduate and Masters Degree level.

| Country

Argentina

Bolivia

Brasil

Chile

Colombia

Costa Rica

Cuba

Ecuador

El Salvador

Guatemala

Honduras

$\begin{array}{cr}\begin{array}{c}\text { Number of } \begin{array}{c}\text { SLIS } \\ \text { Identified } \\ \text { Currently } \\ \text { active }\end{array} \\ 18\end{array} \\ 3 & 15 \\ 50 & 40 \\ 6 & 4 \\ 7 & 4 \\ 4 & 4 \\ 4 & 1 \\ 4 & 3 \\ 2 & 2 \\ 1 & 1 \\ 1 & 1 *\end{array}$

Deleted: chools 


\author{
México \\ Nicaragua \\ Panamá \\ Paraguay \\ Perú \\ Puerto Rico \\ Republica Dominicana \\ Uruguay \\ Venezuela
}

12

1

3

1

3

2

1

1

3

127
11

0

2

1

3

2

2

1

2

100

Table 1. Schools and Departments of Librarianship and Information Sciences in Portuguese- and Spanish-speaking countries in Latin America

* New course proposed to commence in 2007

\section{Limitations}

The researcher was not able to examine the earliest [12] or most recent [13] directories, but it seems unlikely that this has resulted in significant errors or omissions.

In some cases, the URLs included in the appended Directory may link only to a particular course. The aim has been simply to identify institutions where the discipline is or has been taught (or possibly in some cases where it was intended to be taught). No effort has generally been made to provide URLs where courses are offered in an institution at more than one level (undergraduate and postgraduate), or with more than one specialism, in e.g. librarianship, information science, or archives and records management. Schools teaching only archives or records management have not been included unless they already appeared in one of the directories consulted.

Some of the institutions listed here offer their courses both on campus and through distance teaching. In some cases, the distance teaching is managed through a separate department within the institution. This list assumes that the academic development of the course is the responsibility of the cognate department, and separate address details for the distance-learning programme have been omitted.

In almost every country there is some evidence (implicit in the names of courses and Schools) of the shift from teaching curricula narrowly focused on librarianship to more broadly based information studies. This has been accepted in recognising what appears to be the contemporary manifestation of Schools listed in older directories and including them here, although the changing emphasis of their curricula remains a contentious matter in some countries. In many cases, insufficient information was easily accessible on the web site to facilitate the complete elimination from this list those courses teaching "ciencias de informacion" that may be using the term in its equally widely recognised sense to describe degree programmes in computer science.

\section{Acknowledgements}


The author is grateful to the partners in the REVISTAS project for contributing information, and to Elsa Ramirez Leyva of the Centro Universitario de Investigaciones Bibliotecológicas, Universidad Nacional Autónoma de México, whose work on this topic contributed to the list or helped validate some of the information found.

\section{REFERENCES}

1 Linares, E., compiler. Guia de escuelas y cursos de bibliotecologia en America Latina. $2^{\text {nd }}$ edition. Washington, D.C., USA: Union Panamericana. 1959

2 UNESCO. World guide to Library Schools and training courses in documentation. London,U.K.: Bingley. 1972

3 Fang, J.R., and Nauta, P., editors. International guide to Library and Information Science education. Munich, Germany: K.G. Saur. 1985 (IFLA Publication 32)

4 Fang, J.R. Stueart, R.D., and Tuamsak, K., editors. World guide to Library Archive and Information Science education. $2^{\text {nd }}$ edition. Munich, Germany: K.G. Saur. 1995 (IFLA Publications 72/73)

5 Johnson, I.M., and Fuertes Medina, A. Librarianship and Information Studies in Latin America and the Caribbean. Focus on international and comparative librarianship, 31 (2), 2000, 61-70.

6 Maris Fernandez, S., and Giunti, G.M. Planes de estudio de las escuelas de bibliotecología, archivología y museografía de Iberoamérica. Buenos Aires, Argentina: Sociedad de Investigaciones Bibliotecológicas; IFLA, Progreso de la Bibliotecología en el Tercer Mundo/ALP. 1999

7 Rodríguez [Gallardo], [J.] A. Library Science studies in Latin America and the Caribbean: a numerical and interpretative approach - paper presented at the ALISE Conference, Boston, Massachusetts, January 11-14, 2005. [21 PowerPoint slides] [online]: http://dlist.sir.arizona.edu/718/ [Accessed $12^{\text {th }}$ July 2005] 8 Rodríguez Gallardo, [J.] A. Library education in Latin America and the Caribbean. New Library World, 108 (1/2) 2007, 40-54

9 UNESCO. World guide to Library Schools and training courses in documentation. London,U.K.: Bingley. 1972

10 Fang, J.R., and Nauta, P., editors. International Guide to Library and 


\begin{tabular}{|c|c|c|c|}
\hline $\begin{array}{l}\text { Current postal address, } \\
\text { URL and email } \\
\text { J anuary } 2007\end{array}$ & $\begin{array}{l}\text { World } \\
\text { Guide to } \\
\text { Library } \\
\text { Archive } \\
\text { and } \\
\text { Informati } \\
\text { on } \\
\text { Science } \\
\text { Educatio } \\
\text { n, } 1995\end{array}$ & $\begin{array}{l}\text { Internati } \\
\text { onal } \\
\text { Guide to } \\
\text { Library } \\
\text { and } \\
\text { Informati } \\
\text { on } \\
\text { Science } \\
\text { Educatio } \\
\text { n, } 1985\end{array}$ & $\begin{array}{l}\text { World } \\
\text { Guide to } \\
\text { Library } \\
\text { Schools } \\
\text { \& } \\
\text { Training } \\
\text { Courses } \\
\text { in } \\
\text { Documen } \\
\text { tation, } \\
1972 \\
\end{array}$ \\
\hline $\begin{array}{l}\text { Departamento de Bibliotecología y Ciencias de la } \\
\text { Información, } \\
\text { Facultad de Filosofía y Letras, } \\
\text { Universidad de Buenos Aires, } \\
\text { 3er piso, Of 335, } \\
\text { Puan 480, } \\
1424 \text { BUENOS AIRES } \\
\text { Argentina } \\
\text { URL: http://www.filo.uba.ar/ } \\
\text { Email: bibliot@filo.uba.ar }\end{array}$ & $\begin{array}{l}\text { Departament } \\
\text { o de } \\
\text { Bibliotecologí } \\
\text { a y } \\
\text { Documentaci } \\
\text { ón, } \\
\text { Facultad de } \\
\text { Filosofía y } \\
\text { Letras, } \\
\text { Universidad } \\
\text { de Buenos } \\
\text { Aires, } \\
\text { Cuán 470, } \\
\text { 1406 } \\
\text { BUENOS } \\
\text { AIRES } \\
\text { Argentina }\end{array}$ & $\begin{array}{l}\text { Carrera de } \\
\text { Bibliotecologí } \\
\text { a y } \\
\text { Documentaci } \\
\text { ón, } \\
\text { Facultad de } \\
\text { Filosofía y } \\
\text { Letras, } \\
\text { Universidad } \\
\text { de Buenos } \\
\text { Aires, } \\
25 \text { de mayo } \\
217, \\
\text { BUENOS } \\
\text { AIRES } \\
\text { Argentina }\end{array}$ & $\begin{array}{l}\text { Carrera de } \\
\text { Ciencias de } \\
\text { la } \\
\text { Información, } \\
\text { Facultad de } \\
\text { Filosofía y } \\
\text { Letras, } \\
\text { Universidad } \\
\text { de Buenos } \\
\text { Aires, } \\
\text { BUENOS } \\
\text { AIRES } \\
\text { Argentina }\end{array}$ \\
\hline $\begin{array}{l}\text { Escuela de Bibliotecología, } \\
\text { Facultad de Ciencias de la Interacción Social, } \\
\text { Universidad del Museo Social Argentino, } \\
\text { Av. Corrientes No 1723, } \\
\text { C1042AAD BUENOS AIRES } \\
\text { Argentina } \\
\text { URL: } \\
\text { http://www.umsa.edu.ar/facultades/04.00.00.php } \\
\text { Email: informes@umsa.edu.ar }\end{array}$ & $\begin{array}{l}\text { Escuela de } \\
\text { Bibliotecologí } \\
\text { a, } \\
\text { Facultad de } \\
\text { Ciencias de } \\
\text { la } \\
\text { Información } \\
\text { y Opinión, } \\
\text { Universidad } \\
\text { del Museo } \\
\text { Social } \\
\text { Argentino, } \\
\text { Corrientes } \\
\text { 1723, } \\
\text { BUENOS } \\
\text { AIRES } \\
\text { Argentina }\end{array}$ & $\begin{array}{l}\text { Escuela de } \\
\text { Bibliotecologí } \\
\text { a, } \\
\text { Facultad de } \\
\text { Ciencias de } \\
\text { la } \\
\text { Información } \\
\text { y Opinión, } \\
\text { Universidad } \\
\text { del Museo } \\
\text { Social } \\
\text { Argentino, } \\
\text { Corrientes } \\
\text { 1723, } \\
\text { BUENOS } \\
\text { AIRES } \\
\text { Argentina }\end{array}$ & $x$ \\
\hline $\begin{array}{l}\text { Curso de Bibliotecología } \\
\text { Instituto de Educación Superior ABM (Asociación } \\
\text { Biblioteca del Consejo de Mujeres) } \\
\text { Marcelo T de Alvear } 1155 \\
\text { BUENOS AIRES } \\
\text { Argentina } \\
\text { CANNOT FIND WEB SITE }\end{array}$ & $\begin{array}{l}\text { Instituto } \\
\text { Incorporada } \\
\text { ABM, } \\
\text { Marcelo T de } \\
\text { Alvear 1155, } \\
\text { BUENOS } \\
\text { AIRES } 1058 \\
\text { Argentina }\end{array}$ & $\begin{array}{l}\text { Curso de } \\
\text { Bibliotecologí } \\
\text { a, } \\
\text { Sección } \\
\text { Cursos, } \\
\text { Biblioteca del } \\
\text { Consejo de } \\
\text { Mujeres, } \\
\text { Marcelo T de } \\
\text { Alvear 1155, } \\
\text { BUENOS } \\
\text { AIRES } \\
\text { Argentina }\end{array}$ & $x$ \\
\hline
\end{tabular}




\begin{tabular}{|c|c|c|c|}
\hline $\begin{array}{l}\text { Escuela Nacional de Bibliotecarios } \\
\text { Biblioteca Nacional de la Republica, } \\
\text { Agüero } 2502 \text { - (C1425EID) } \\
\text { BUENOS AIRES } \\
\text { Argentina } \\
\text { URL: } \\
\text { http://www.bibnal.edu.ar/PAGINAS/escueladebibli } \\
\text { o.htm } \\
\text { Email: escuelabib@red.bibnal.edu.ar }\end{array}$ & $x$ & $\begin{array}{l}\text { Escuela } \\
\text { Nacional de } \\
\text { Bibliotecarios } \\
\text { '́subsecretarí } \\
\text { a de Cultura } \\
\text { de la Nación, } \\
\text { México 564, } \\
\text { BUENOS } \\
\text { AIRES } \\
\text { Argentina }\end{array}$ & $x$ \\
\hline $\begin{array}{l}\text { Perito en Documentología } \\
\text { Facultad de Ciencias de la Criminalística } \\
\text { Instituto Universitario de la Policia Federal } \\
\text { Argentina } \\
\text { Rosario } 532 \\
\text { BUENOS AIRES } \\
\text { Argentina } \\
\text { URL: http://www.universidad- } \\
\text { policial.edu.ar/txt_fondos/fac_criminalistica/pregra } \\
\text { do_perito_doc.html } \\
\text { Email: }\end{array}$ & & & \\
\hline $\begin{array}{l}\text { Escuela de Bibliotecarios, } \\
\text { Facultad de Filosofía y Humanidades, } \\
\text { Universidad Nacional de Córdoba, } \\
\text { Ciudad Universitaria, } \\
\text { Estafeta 32, } \\
5000 \text { CÓRDOBA } \\
\text { Argentina } \\
\text { URL: http://www.ffyh.unc.edu.ar/index2.php } \\
\quad \text { http://www.bibliofilia.com.ar/escuela.htm } \\
\text { Email: interfilo@ffyh.unc.edu.ar }\end{array}$ & $\begin{array}{l}\text { Escuela de } \\
\text { Bibliotecarios } \\
\text { '́ } \\
\text { Facultad de } \\
\text { Filosofía y } \\
\text { Humanidade } \\
\text { s, } \\
\text { Universidad } \\
\text { Nacional de } \\
\text { Córdoba, } \\
\text { Ciudad } \\
\text { Universitaria, } \\
\text { Estafeta 32, } \\
\text { 5000 } \\
\text { CóRDOBA } \\
\text { Argentina }\end{array}$ & $\begin{array}{l}\text { Escuela de } \\
\text { Bibliotecarios } \\
\text { ' } \\
\text { Facultad de } \\
\text { Filosofía y } \\
\text { Humanidade } \\
\text { s, } \\
\text { Universidad } \\
\text { Nacional de } \\
\text { Córdoba, } \\
\text { Pabellón } \\
\text { Espaňa, } \\
\text { Ciudad } \\
\text { Universitaria, } \\
\text { Casilla de } \\
\text { Correo 32, } \\
\text { CÓRDOBA } \\
\text { Argentina }\end{array}$ & $\begin{array}{l}\text { Escuela de } \\
\text { Bibliotecarios } \\
\text { 'Facultad de } \\
\text { Filosofía y } \\
\text { Humanidade } \\
\text { s, } \\
\text { Universidad } \\
\text { Nacional de } \\
\text { Córdoba, } \\
\text { Pabellón } \\
\text { Espaňa, } \\
\text { Ciudad } \\
\text { Universitaria, } \\
\text { Casilla de } \\
\text { Correo 30, } \\
\text { CÓRDOBA } \\
\text { Argentina }\end{array}$ \\
\hline
\end{tabular}




\begin{tabular}{|c|c|c|c|}
\hline $\begin{array}{l}\text { Departamento de Bibliotecología, } \\
\text { Facultad de Humanidades y Ciencias de la } \\
\text { Educación, } \\
\text { Universidad Nacional de La Plata, } \\
\text { Calle } 48 \text { e/6 y 7, } \\
1900 \text { LA PLATA, } \\
\text { Buenos Aires, } \\
\text { Argentina } \\
\text { URL: } \\
\text { http://www.fahce.unlp.edu.ar/departamentos/dhu } \\
\text { bi/paginas/portada1.htm } \\
\text { Email: dhubi@huma.fahce.unlp.edu.ar }\end{array}$ & $\begin{array}{l}\text { Departament } \\
\text { o de } \\
\text { Bibliotecologí } \\
\text { a, } \\
\text { Facultad de } \\
\text { Humanidade } \\
\text { s y Ciencias } \\
\text { de la } \\
\text { Educación, } \\
\text { Universidad } \\
\text { Nacional de } \\
\text { La Plata, } \\
\text { Calle } 48 \\
\text { entre } 6 \text { y } 7, \\
\text { Of } 524, \\
1900 \text { LA } \\
\text { PLATA } \\
\text { Argentina }\end{array}$ & $\begin{array}{l}\text { Departament } \\
\text { o de } \\
\text { Bibliotecologí } \\
\text { a, } \\
\text { Facultad de } \\
\text { Humanidade } \\
\text { s y Ciencias } \\
\text { de la } \\
\text { Educación, } \\
\text { Universidad } \\
\text { Nacional de } \\
\text { La Plata, } \\
\text { Calle 7, casi } \\
\text { esq Calle } \\
\text { 48, } \\
\text { 1900 LA } \\
\text { PLATA } \\
\text { Argentina }\end{array}$ & $\begin{array}{l}\text { Escuela de } \\
\text { Bibliotecarios } \\
\text { Úniversidad } \\
\text { Nacional de } \\
\text { La Plata, } \\
\text { Plaza Rocha, } \\
\text { 137, } \\
\text { LA PLATA } \\
\text { Buenos } \\
\text { Aires, } \\
\text { Argentina }\end{array}$ \\
\hline $\begin{array}{l}\text { Carreras de Bibliotecología - Museología - } \\
\text { Archivología } \\
\text { Instituto Superior de Formación Docente y Técnica } \\
\text { No } 8 \\
\text { Ministerio de Educación de la Provincia de Buenos } \\
\text { Aires, } \\
\text { Dirección de Eseňanza Superior, } \\
\text { Calle } 45 \text { No } 866 \text { e/ } 12 \text { y } 13 \\
1900 \text { LA PLATA } \\
\text { Buenos Aires, } \\
\text { Argentina } \\
\text { URL: } \\
\text { http://abc.gov.ar/paginaescuela/0001IS0008/ } \\
\text { Email: is001008@abc.gov.ar }\end{array}$ & $x$ & $\begin{array}{l}\text { Instituto } \\
\text { Superior de } \\
\text { Formación } \\
\text { Docente en } \\
\text { Bibliotecologí } \\
\text { a, } \\
\text { Ministerio de } \\
\text { Educación de } \\
\text { la Provincia } \\
\text { de Buenos } \\
\text { Aires, } \\
\text { Dirección de } \\
\text { Eseňanza } \\
\text { Superior, } \\
\text { Diagonal 74, } \\
\text { 1052/58, } \\
\text { 1900 LA } \\
\text { PLATA } \\
\text { Buenos } \\
\text { Aires, } \\
\text { Argentina }\end{array}$ & $\begin{array}{l}\text { Escuela } \\
\text { Superior de } \\
\text { Bibliotecologí } \\
\text { a, } \\
\text { Ministerio de } \\
\text { Educación de } \\
\text { la Provincia } \\
\text { de Buenos } \\
\text { Aires, } \\
\text { Dirección de } \\
\text { Enseňanza } \\
\text { Superior, } \\
\text { Calle 44 } \\
\text { no790, } \\
\text { LA PLATA, } \\
\text { Buenos } \\
\text { Aires, } \\
\text { Argentina }\end{array}$ \\
\hline $\begin{array}{l}\text { Departamento de Documentación } \\
\text { Facultad de Humanidades } \\
\text { Universidad Nacional de Mar del Plata } \\
\text { Funes } 3350 \\
\text { CP } 7600 \\
\text { MAR DEL PLATA } \\
\text { Argentina } \\
\text { URL: } \\
\text { http://www.mdp.edu.ar/humanidades/documentac } \\
\text { ion/ } \\
\text { Email: humana@mdp.edu.ar }\end{array}$ & $x$ & $x$ & $x$ \\
\hline
\end{tabular}




\begin{tabular}{|c|c|c|c|}
\hline $\begin{array}{l}\text { Carrera de Bibliotecología, } \\
\text { Facultad de Humanidades "Teresa de Ávila", } \\
\text { Pontificia Universidad Católica Argentina "Santa } \\
\text { Maria de los Buenos Aires", } \\
\text { Buenos Aires } 249 \\
3100 \text { PARANÁ } \\
\text { Entre Ríos, } \\
\text { Argentina } \\
\text { URL: http://www2.uca.edu.ar/esp/sec- } \\
\text { parana/esp/page.php?subsec=carreras\&page=c- } \\
\text { grado/c-grado-plan\&sede=parana\&plan=avila- } \\
\text { bibliotecologia } \\
\text { Email: infohumanidades@arnet.com.ar }\end{array}$ & $x$ & $x$ & $x$ \\
\hline $\begin{array}{l}\text { Departamento de Bibliotecología } \\
\text { Facultad de Humanidades y Ciencias Sociales } \\
\text { Universidad Nacional de Misiones } \\
\text { Tucumán } 1946 \\
3300 \text { POSADAS, } \\
\text { Misiones } \\
\text { Argentina } \\
\text { URL: } \\
\text { http://www.fhycs.unam.edu.ar/content/view/32/4 } \\
\text { 1/ } \\
\text { Email: }\end{array}$ & $\begin{array}{l}\text { Carrera de } \\
\text { Bibliotecologí } \\
\text { a, } \\
\text { Facultad de } \\
\text { Humanidade } \\
\text { s y Ciencias } \\
\text { Sociales, } \\
\text { Universidad } \\
\text { Nacional de } \\
\text { Misiones, } \\
\text { Tucumán, } \\
448 \\
3300 \\
\text { POSADAS, } \\
\text { Misiones, } \\
\text { Argentina }\end{array}$ & $\begin{array}{l}\text { Carrera de } \\
\text { Bibliotecologí } \\
\text { a, } \\
\text { Facultad de } \\
\text { Humanidade } \\
\text { s y Ciencias } \\
\text { Sociales, } \\
\text { Universidad } \\
\text { Nacional de } \\
\text { Misiones, } \\
\text { Tucumán } \\
448 \\
3300 \\
\text { POSADAS, } \\
\text { Misiones, } \\
\text { Argentina }\end{array}$ & $x$ \\
\hline $\begin{array}{l}\text { Departamento de Ciencias de I'Informacion, } \\
\text { Facultad de Humanidades, } \\
\text { Universidad Nacional del Nordeste, } \\
\text { Av. Las Heras 727, } \\
\text { RESISTENCIA, } \\
\text { Chaco CP } 3500 \\
\text { Argentina } \\
\text { URL: } \\
\text { http://hum.unne.edu.ar/academica/departamento } \\
\text { s/informac/index.htm } \\
\text { Email: informa@hum.unne.edu.ar }\end{array}$ & $\begin{array}{l}\text { Carrera a } \\
\text { Término de } \\
\text { Bibliotecarios } \\
\text { '́irección de } \\
\text { Bibliotecas, } \\
\text { Universidad } \\
\text { Nacional del } \\
\text { Nordeste } \\
\text { (UNNE), } \\
\text { Las Heras } \\
727, \\
3500 \\
\text { RESISTENCI } \\
\text { A, } \\
\text { Chaco, } \\
\text { Argentina }\end{array}$ & $\begin{array}{l}\text { Dirección de } \\
\text { Bibliotecas } \\
\text { de UNNE, } \\
\text { Universidad } \\
\text { Nacional del } \\
\text { Nordeste } \\
\text { (UNNE), } \\
\text { Las Heras } \\
727, \\
3500 \\
\text { RESISTENCI } \\
\text { A, } \\
\text { Chaco, } \\
\text { Argentina }\end{array}$ & $\begin{array}{l}\text { Escuela a } \\
\text { Término de } \\
\text { Bibliotecarios } \\
\text { '́irección de } \\
\text { Bibliotecas, } \\
\text { Universidad } \\
\text { Nacional del } \\
\text { Nordeste, } \\
\text { Av. Las } \\
\text { Heras 727, } \\
\text { RESISTENCI } \\
\text { A, } \\
\text { Chaco, } \\
\text { Argentina }\end{array}$ \\
\hline
\end{tabular}




\begin{tabular}{|c|c|c|c|}
\hline $\begin{array}{l}\text { Postitulo de Formacion Universitaria en } \\
\text { Bilbliotecologia y Documentacion } \\
\text { Facultad de Humanidades y Artes, } \\
\text { Universidad Nacional de Rosario } \\
\text { Entre Ríos 758, } \\
\text { CP } 2000 \text { ROSARIO } \\
\text { Argentina } \\
\text { URL: } \\
\text { http://www.fhumyar.unr.edu.ar/index.php?id=pos } \\
\text { titulo } \\
\text { Email: tbertain@fhumyar.unr.edu.ar }\end{array}$ & $\begin{array}{l}\text { Departament } \\
\text { o de } \\
\text { Bibliotecologí } \\
\text { a, } \\
\text { Facultad de } \\
\text { Filosofía, } \\
\text { Universidad } \\
\text { Nacional de } \\
\text { Rosario, } \\
\text { Entre Ríos } \\
758 \\
\text { ROSARIO } \\
\text { Argentina }\end{array}$ & $\begin{array}{l}\text { Carrera de } \\
\text { Bibliotecario, } \\
\text { Departament } \\
\text { o de } \\
\text { Bibliotecologí } \\
\text { a, } \\
\text { Facultad de } \\
\text { Filosofía, } \\
\text { Universidad } \\
\text { Nacional de } \\
\text { Rosario, } \\
\text { Entre Ríos } \\
758 \\
\text { ROSARIO } \\
\text { Argentina }\end{array}$ & \begin{tabular}{|l} 
Escuela de \\
Bibliotecologí \\
a, \\
Facultad de \\
Filosofía, \\
Universidad \\
Nacional de \\
Rosario, \\
Entre Ríos \\
758 \\
ROSARIO \\
Argentina
\end{tabular} \\
\hline $\begin{array}{l}\text { Escuela de Bibliotecarios, } \\
\text { Instituto de Profesiones Técnicas "20 de Junio", } \\
\text { Ministerio de Educación y Cultura de la Provincia } \\
\text { de Santa Fe, } \\
\text { Servicio de Eseňanza Superior, } \\
\text { Normal, Media y Técnica, } \\
\text { Moreno 965, } \\
2 \text { piso, } \\
2000 \text { ROSARIO } \\
\text { Argentina } \\
\text { CANNOT FIND WEB SITE }\end{array}$ & & $\begin{array}{l}\text { Escuela de } \\
\text { Bibliotecarios } \\
\text { '́nstituto de } \\
\text { Insofesiones } \\
\text { Técnicas "20 } \\
\text { de Junio", } \\
\text { Ministerio de } \\
\text { Educación y } \\
\text { Cultura de la } \\
\text { Provincia de } \\
\text { Santa Fe, } \\
\text { Servicio de } \\
\text { Eseňanza } \\
\text { Superior, } \\
\text { Normal, } \\
\text { Media y } \\
\text { Técnica, } \\
\text { Moreno } 965, \\
2 \text { piso, } \\
2000 \\
\text { ROSARIO } \\
\text { Argentina }\end{array}$ & \\
\hline $\begin{array}{l}\text { Escuela de Bibliotecología "Mariano Moreno" } \\
\text { Ministerio de Cultura y Educación de San Juan } \\
\text { Dirección de Enseñanza Superior, Media y Técnica } \\
\text { Avenida Libertador San Martín } 381 \text { Oeste } \\
5400 \text { SAN JUAN } \\
\text { Argentina } \\
\text { URL: CANNOT FIND WEB SITE } \\
\text { Email: bibliotecologia@sinectis.com.ar }\end{array}$ & $\begin{array}{l}\text { Escuela de } \\
\text { Bibliotecologí } \\
\text { a "Mariano } \\
\text { Moreno", } \\
\text { Ministerio de } \\
\text { Educación y } \\
\text { Cultura de } \\
\text { San Juan, } \\
\text { Avenida } \\
\text { Libertador } \\
\text { San Martín } \\
381 \text { Oeste } \\
5400 \text { SAN } \\
\text { JUAN } \\
\text { Argentina }\end{array}$ & $\begin{array}{l}\text { Escuela de } \\
\text { Bibliotecologí } \\
\text { a "Mariano } \\
\text { Moreno", } \\
\text { Media y } \\
\text { Técnica, } \\
\text { Dirección de } \\
\text { Eseňanza } \\
\text { Superior, } \\
\text { Consejo } \\
\text { General de } \\
\text { Educación, } \\
\text { Gral. Acha } \\
\text { 426 Sur, } \\
\text { SAN JUÁN } \\
\text { Argentina }\end{array}$ & $x$ \\
\hline
\end{tabular}




\begin{tabular}{|c|c|}
\hline $\begin{array}{l}\text { Tecnicatura Universitaria en Documentología } \\
\text { Facultad de Psicología } \\
\text { Universidad del Aconcagua } \\
\text { Colegio Nuestra Señora Del Libano } \\
\text { Arjonilla 50 } \\
\text { SAN MARTIN } \\
\text { Argentina } \\
\text { URL: } \\
\text { http://www.uda.edu.ar/home/ver_carrera_new.as } \\
\text { p?codigoCarrera=19\&codigoFacultad=2 } \\
\text { Email: fpsico@uda.edu.ar }\end{array}$ & \\
\hline $\begin{array}{l}\text { Ciclo de Licenciatura en Bibliotecología } \\
\text { Facultad de Ciencias Jurídicas y Sociales (FCJS) } \\
\text { Universidad Nacional del Litoral } \\
\text { Cándido Pujato } 2751 \\
\text { SANTA FE } \\
\text { Santa Fe } \\
\text { Argentina } \\
\text { URL: } \\
\text { http://www.fcjs.unl.edu.ar/?action=carreras.view\& } \\
\text { id=3\&ids=84 } \\
\text { Email: educacionadistancia@fcjs.unl.edu.ar }\end{array}$ & $\begin{array}{l}\text { Instituto } \\
\text { Superior de } \\
\text { Bibliotecologí } \\
\text { a, } \\
\text { Ministerio de } \\
\text { Cultura y } \\
\text { Educación de } \\
\text { la Provincia } \\
\text { de Santa Ge, } \\
\text { Saavedra } \\
\text { 3076, } \\
\text { SANTA FE } \\
\text { Argentina }\end{array}$ \\
\hline $\begin{array}{l}\text { Técnico Universitario en Documentación y } \\
\text { Museología Arqueológica } \\
\text { Facultad de Ciencias Naturales e Instituto Miguel } \\
\text { Lillo } \\
\text { Universidad Nacional de Tucumán } \\
\text { Calle Miguel Lillo } 205 \\
\text { CP. } 4000 \\
\text { TUCUMÁN Capital } \\
\text { Argentina } \\
\text { URL: } \\
\text { Email: }\end{array}$ & \\
\hline
\end{tabular}

\section{Curso Técnico Superior en Bibliotecología}

Fac. de Humanidades y Ciencias de la Educación Universidad Mayor de San Simón,

Casilla 992

COCHABAMBA

Bolivia

URL: http://www.umss.edu.bo/facultades.php http://www.umsanet.edu.bo/cie-inf/ Email:

\section{CANNOT VERIFY COURSE CURRENTLY OFFERED}


Carrera de Bibliotecología y Ciencias de la Información

Facultad de Humanidades y Ciencias de la

Educación

Universidad Mayor de San Andrés,

Casa Montes 1er Piso

Avenida 6 de Agosto, 2080,

Cajón Postal 1386

LA PAZ

Bolivia

URL:

http://fhce.umsa.bo/fhce/app?service= page/Id010

2

Email: bibliotecologia@humanidades.edu.bo

Curso de Bibliotecología

La Dirección Nacional de Bibliotecas (ex-Banco del Libro)

Junin $N^{\circ} 608$

Casilla 11092

LA PAZ

Bolivia

CANNOT TRACE CURRENT WEB PAGE FOR THIS COURSE

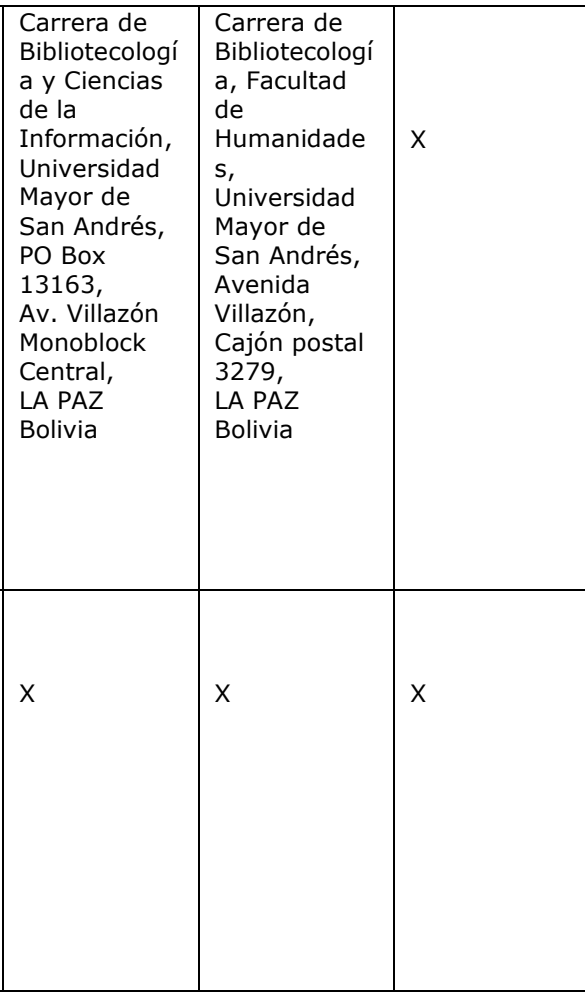

Curso de Bibliotecología

Universidade Tiradentes

Rua Lagarto

ARACAJU

Sergipe CEP 49010 - 390

Brasil

URL: http://www.unit.br/

Email:

CANNOT TRACE CURRENT WEB PAGE FOR THIS

COURSE

\begin{tabular}{|l|l|l|}
\hline$x$ & $x$ & $x$ \\
& & \\
\hline
\end{tabular}




\begin{tabular}{|c|c|c|c|}
\hline $\begin{array}{l}\text { Curso de Biblioteconomía } \\
\text { Universidade Federal do Pará } \\
\text { Centro Sócio-Econômico } \\
\text { Pavilhão 1-9 } \\
\text { Campus Universitário - Guamá } \\
\text { Rua Augusto Corrêa, } 01 \\
\text { BELÉM } \\
\text { Pará CEP 66075-900 } \\
\text { Brasil } \\
\text { URL: http://www.ufpa.br/biblio/ } \\
\text { Email: cse@ufpa.br }\end{array}$ & $x$ & $\begin{array}{l}\text { Departament } \\
\text { o de } \\
\text { Bibliotecono } \\
\text { mia, } \\
\text { Centro Sócio } \\
\text { Econômico, } \\
\text { Universidade } \\
\text { Federal do } \\
\text { Pará, } \\
\text { Campus } \\
\text { Universitário, } \\
66000 \\
\text { BELEM, } \\
\text { Pará } \\
\text { Brazil }\end{array}$ & $x$ \\
\hline
\end{tabular}

\begin{tabular}{|c|c|c|c|}
\hline $\begin{array}{l}\text { Curso de Ciência da Informação } \\
\text { Instituto de Informática } \\
\text { Pontifícia Universidade Católica de Minas Gerais } \\
\text { Campus do Coração Eucarístico } \\
\text { Av. Dom José Gaspar, } 500 \text { - Prédio } 34 \\
\text { BELO HORIZONTE } \\
\text { Minas Gerais CEP 30535-610 } \\
\text { Brasil } \\
\text { URL: } \\
\text { http://www.pucminas.br/cursos/index_graduacao. } \\
\text { php?tipo=1\&pagina=3\&menu=53\&cabecalho=1\&la } \\
\text { teral=1\&curso=76 } \\
\text { Email: secdcc@pucminas.br }\end{array}$ & $X$ & $x$ & $X$ \\
\hline $\begin{array}{l}\text { Escola de Ciência da Informação } \\
\text { Universidade Federal de Minas Gerais } \\
\text { Av Antonio Carlos, } 6227 \\
\text { Cidade Universitaria, } \\
\text { Caixa Postal } 1606 \\
\text { BELO HORIZONTE } \\
\text { Minas Gerais CEP } 31270-901 \\
\text { Brasil } \\
\text { URL: http://www.eci.ufmg.br/ } \\
\text { Email: dir@eci.ufmg.br }\end{array}$ & $X$ & $\begin{array}{l}\text { Escola de } \\
\text { Bibliotecono } \\
\text { mía, } \\
\text { Universidade } \\
\text { Federal de } \\
\text { Minas Gerais, } \\
\text { Avenida } \\
\text { Antonio } \\
\text { Carlos } 6627, \\
\text { Caixa Postal } \\
1906, \\
\text { PAMPULHA, } \\
\text { Minas Gerals } \\
\text { Brazil }\end{array}$ & $\begin{array}{l}\text { Escola de } \\
\text { Bibliotecono } \\
\text { mía, Retoria, } \\
\text { Universidade } \\
\text { Federal de } \\
\text { Minas Gerais, } \\
\text { Pampulha, } \\
\text { BELO } \\
\text { HORIZONTE, } \\
\text { Minas Gerais } \\
\text { CP 1906 } \\
\text { Brazil }\end{array}$ \\
\hline
\end{tabular}




\begin{tabular}{|c|c|c|c|}
\hline $\begin{array}{l}\text { Departamento de Ciência da Informação } \\
\text { Faculdade de Economia, Administração, } \\
\text { Contabilidade e Ciência da Informação } \\
\text { Universidade de Brasilia } \\
\text { Campus Universitario } \\
\text { Asa Norte, } \\
\text { Caixa Postal } 04561 \\
\text { BRASILIA DF 70919-970 } \\
\text { Brasil } \\
\text { URL: http://www.unb.br/fa/cid/ } \\
\text { Email: cid@unb.br }\end{array}$ & $\begin{array}{l}\text { Departament } \\
\text { o de } \\
\text { Bibliotecono } \\
\text { mia, } \\
\text { Faculdade de } \\
\text { Estudos } \\
\text { Socias } \\
\text { Aplicados, } \\
\text { Universidade } \\
\text { de Brasília, } \\
\text { Caixa Postal } \\
\text { 15-3011, } \\
\text { 70910 } \\
\text { BRASILIA, } \\
\text { DF } \\
\text { Brazil }\end{array}$ & $\begin{array}{l}\text { Departament } \\
\text { o de } \\
\text { Bibliotecono } \\
\text { mia, } \\
\text { Faculdade de } \\
\text { Estudos } \\
\text { Socias } \\
\text { Aplicados, } \\
\text { Universidade } \\
\text { de Brasília, } \\
\text { Campus } \\
\text { Universitário, } \\
\text { CP 153011, } \\
\text { 70919 } \\
\text { BRASILIA, } \\
\text { DF } \\
\text { Brazil } \\
\end{array}$ & $\begin{array}{l}\text { Departament } \\
\text { o de } \\
\text { Bibliotecono } \\
\text { mía, } \\
\text { Faculdade de } \\
\text { Estudos } \\
\text { Sociais } \\
\text { Aplicados, } \\
\text { Universidad } \\
\text { de Brasília, } \\
\text { Agência } \\
\text { Postal 15, } \\
\text { Campus } \\
\text { Universitário, } \\
\text { BRASÍLIA, } \\
\text { DF } \\
\text { Brazil } \\
\end{array}$ \\
\hline $\begin{array}{l}\text { Faculdade de Biblioteconomia, } \\
\text { Pontificia Universidade Catolica de Campinas, } \\
\text { Rua Marechal Deodoro, 1099, } \\
\text { Centro } \\
\text { Caixa Postal } 317 \\
\text { CAMPINAS, } \\
\text { Sao Paulo CEP 13020-904 } \\
\text { Brasil } \\
\text { URL: http://www.puc- } \\
\text { campinas.br/graduacao/curso_01.asp?id=13 } \\
\text { Email: biblio@puc-campinas.edu.br }\end{array}$ & $x$ & $\begin{array}{l}\text { Faculdade de } \\
\text { Bibliotecono } \\
\text { mia, } \\
\text { Pontificia } \\
\text { Universidade } \\
\text { Católica de } \\
\text { Campinas, } \\
\text { R Marechal } \\
\text { Deodoro, } \\
1099, \\
\text { Caixa Postal } \\
317 \\
\text { CAMPINAS, } \\
13,100, \\
\text { Sao Paulo } \\
\text { Brazil }\end{array}$ & $\begin{array}{l}\text { Faculdade de } \\
\text { Bibliotecono } \\
\text { mía, } \\
\text { Universidade } \\
\text { Católica de } \\
\text { Campinas, } \\
\text { Rua Marechal } \\
\text { Deodoro } \\
1099, \\
\text { CP } 317, \\
\text { CAMPINAS, } \\
\text { Est de São } \\
\text { Paulo, } \\
\text { Brazil }\end{array}$ \\
\hline $\begin{array}{l}\text { Curso de Biblioteconomía } \\
\text { Instituto Superior da Funlec - ISF } \\
\text { Rua Cassildo Arantes, } 322 \\
\text { Bairro Cachoeira } \\
\text { CAMPO GRANDE } \\
\text { Mato Grosso do Sul CEP: } 79040-450 \\
\text { Brasil } \\
\text { URL: } \\
\text { http://www.funlec.edu.br/Graduação/CursodeBibli } \\
\text { oteconomia/tabid/70/Default.aspx } \\
\text { Email: iesf@zaz.com.br }\end{array}$ & $X$ & $x$ & $x$ \\
\hline $\begin{array}{l}\text { Curso de Biblioteconomia, } \\
\text { Faculdade de Filosofia, Ciências e Letras de } \\
\text { Catanduva, } \\
\text { Instituto Municipal de Ensino Superior de } \\
\text { Catanduva } \\
\text { Rua Maranhão, } 898 \\
\text { CATANDUVA } \\
\text { Sao Paulo 15,000 } \\
\text { Brazil } \\
\text { URL: http://www.fafica.br/ } \\
\text { CANNOT TRACE CURRENT WEB PAGE FOR THIS } \\
\text { COURSE }\end{array}$ & & $\begin{array}{l}\text { Curso de } \\
\text { Bibliotecono } \\
\text { mia, } \\
\text { Faculdade de } \\
\text { Filosofia, } \\
\text { Ciências e } \\
\text { Letras de } \\
\text { Catanduva, } \\
\text { Rua } \\
\text { Seminário } \\
281, \\
\text { Caixa Postal } \\
86, \\
\text { CATANDUVA } \\
\text { Sao Paulo } \\
15,000 \\
\text { Brazil }\end{array}$ & \\
\hline
\end{tabular}




\begin{tabular}{|c|c|c|c|}
\hline $\begin{array}{l}\text { Comissao de Curso de Biblioteconomía } \\
\text { Faculdades Integradas Candido Rondon } \\
\text { Av Beira Rio, 3001, } \\
\text { Jardim Europa } \\
\text { CUIABA } \\
\text { Mato Grosso CEP 78065-780 } \\
\text { Brasil } \\
\text { URL: http://www.unirondon.br/index.php } \\
\text { Email: luzia@unirondon.br } \\
\text { CANNOT TRACE CURRENT WEB PAGE FOR THIS } \\
\text { COURSE }\end{array}$ & $x$ & $x$ & $x$ \\
\hline $\begin{array}{l}\text { Curso de Biblioteconomía } \\
\text { Departamento de Ciência da Informação } \\
\text { Instituto de Ciências Humanas e Sociais } \\
\text { Universidade Federal do Mato Grosso } \\
\text { Campus do Rondonopolis } \\
\text { Av Fernando Corrêa da Costa, s/n - Coxipó da } \\
\text { Ponte } \\
\text { CUIABÁ, } \\
\text { Mato Grosso CEP: } 78060-900 \\
\text { Brasil } \\
\text { URL: } \\
\text { http://www.ufmt.br/rondonopolis/htm/bibliotecon } \\
\text { omia.htm } \\
\text { Email: jamacama@zaz.com.br }\end{array}$ & $x$ & $x$ & $x$ \\
\hline $\begin{array}{l}\text { Curso de Gestao de Informacao } \\
\text { Setor de Ciencias Socais Aplicadas } \\
\text { Universidade Federal do Paraná } \\
\text { Av. Prefeito Lothário Meissner, } 3400 \\
\text { Jd. Botânico } \\
\text { CURITIBA } \\
\text { Parana } 80210-170 \\
\text { Brasil } \\
\text { URL: http://www.decigi.ufpr.br/ } \\
\text { Email: sociais@sociais.ufpr.br }\end{array}$ & $x$ & $\begin{array}{l}\text { Curso de } \\
\text { Bibliotecono } \\
\text { mia e } \\
\text { Documentac } \\
\text { ao, } \\
\text { Departament } \\
\text { o de } \\
\text { Bibliotecono } \\
\text { mia (DEBI), } \\
\text { Setor de } \\
\text { Educaço, } \\
\text { Universidade } \\
\text { Federal do } \\
\text { Paraná, } \\
\text { Rua General } \\
\text { Carneiro } \\
460-7 \text { Andar, } \\
\text { Caixa Postal } \\
1331, \\
\text { CURITIBA, } \\
\text { Paraná } \\
80,000 \\
\text { Brazil }\end{array}$ & $x$ \\
\hline
\end{tabular}




\begin{tabular}{|c|c|c|c|}
\hline $\begin{array}{l}\text { Departamento de Ciencia da Informacao, } \\
\text { Universidade Federal de Santa Catarina } \\
\text { Campus de Trinidade } \\
\text { Caixa Postal } 476 \\
\text { FLORIANAPOLIS } \\
\text { Santa Catarina CEP 88040-970 } \\
\text { Brasil } \\
\text { URL: http://www.cin.ufsc.br/ } \\
\text { Email: dptcin@ced.ufsc.br }\end{array}$ & url: & $\begin{array}{l}\text { Curso de } \\
\text { Bibliotecono } \\
\text { mia e } \\
\text { Documentaç } \\
\text { ao, } \\
\text { Centro } \\
\text { Socio- } \\
\text { Economico, } \\
\text { Universidade } \\
\text { Federal de } \\
\text { Santa } \\
\text { Catarina, } \\
\text { Campus } \\
\text { Universitário- } \\
\text { Trinidade, } \\
\text { FLORIANÁPO } \\
\text { LIS, } \\
\text { Santa } \\
\text { Catarina } \\
88,000 \\
\text { Brazil }\end{array}$ & $x$ \\
\hline $\begin{array}{l}\text { Curso de Biblioteconomía - Gestão da Informação } \\
\text { Centro de Ciências da Educação (CCE-FAED) } \\
\text { Universidade do Estado de Santa Catarina } \\
\text { Av Madre Benvenuta, } 2007 \\
\text { Itacorubi } \\
\text { FLORIANÓPOLIS } \\
\text { Santa Catarina CEP 88035-001 } \\
\text { Brasil } \\
\text { URL: http://www.faed.udesc.br/CursoBiblio/ } \\
\text { Email: r4nsp@udesc.br }\end{array}$ & $x$ & $\begin{array}{l}\text { Curso de } \\
\text { Bibliotecono } \\
\text { mia, } \\
\text { Faculdade de } \\
\text { Educaco, } \\
\text { Universidade } \\
\text { para o } \\
\text { Desenvolvimi } \\
\text { ento do } \\
\text { Estado de } \\
\text { Santa } \\
\text { Catarina } \\
\text { (UDESC), } \\
\text { Rua } \\
\text { Saldanha } \\
\text { Marinho, } \\
\text { 47 } \\
\text { FLORIANAPO } \\
\text { LIS, } \\
\text { Santa } \\
\text { Catarina } \\
\text { Brazil }\end{array}$ & $x$ \\
\hline $\begin{array}{l}\text { Habilitação em Gestão da Informação } \\
\text { Centro de Educação Superior - UNICA } \\
\text { Sociedad Educacional de Santa Catarina e } \\
\text { Fundacao Getulio Vargas } \\
\text { Campus Florianopolis } \\
\text { Rua Salvatina Feliciana dos Santos, } 525 \\
\text { Bairro Itacorubi } \\
\text { FLORIANÓPOLIS } \\
\text { Santa Catarina CEP 88034-001 } \\
\text { Brasil } \\
\text { URL: } \\
\text { http://www.unica.br/cursos/gestao_informacao.ht } \\
\text { m } \\
\text { Email: http://www.webmail.unica.br/ } \\
\text { CANNOT TRACE CURRENT WEB PAGE FOR THIS } \\
\text { COURSE }\end{array}$ & & & \\
\hline
\end{tabular}




\begin{tabular}{|c|c|c|c|}
\hline $\begin{array}{l}\text { Escola de Biblioteconomía } \\
\text { Instituto de Ciências Sociais Aplicadas e Exatas } \\
\text { Centro Universitário de Formiga } \\
\text { Av Dr Armando de Sena, } 328 \\
\text { Agua Vermelha, } \\
\text { Caixa Postal } 102 \\
\text { FORMIGA } \\
\text { Minas Gerais CEP: } 35570-000 \\
\text { Brasil } \\
\text { URL: http://www.uniformg.edu.br/ } \\
\text { Email: coordbiblioteconomia@uniformg.edu.br }\end{array}$ & $x$ & $\begin{array}{l}\text { Escola de } \\
\text { Bibliotecono } \\
\text { mia, Fundaço } \\
\text { de Ensino } \\
\text { Superior do } \\
\text { Oeste de } \\
\text { Minas Gerais, } \\
\text { Rua Barao de } \\
\text { Piumhy, 247, } \\
37,290 \\
\text { FORMIGA, } \\
\text { Minas Gerais, } \\
\text { Brazil }\end{array}$ & $x$ \\
\hline
\end{tabular}

\begin{tabular}{|c|c|c|c|}
\hline $\begin{array}{l}\text { Departamento de Ciencias da Informacao } \\
\text { Universidade Federal do Ceara } \\
\text { Centro de Humanidades } \\
\text { Av da la Universidade, } 2762 \text { - Benfica, } \\
\text { FORTALEZA } \\
\text { Ceara 600200-181 } \\
\text { Brasil } \\
\text { URL: http://www.dci.ufc.br/ } \\
\text { Email: dci@.ufc.br }\end{array}$ & $\begin{array}{l}\text { Coordenação } \\
\text { do Curso de } \\
\text { Bibliotecono } \\
\text { mia, } \\
\text { Centro de } \\
\text { Humanidade } \\
\text { s, } \\
\text { Universidade } \\
\text { Federal do } \\
\text { Ceará, } \\
\text { Av da } \\
\text { Universidade } \\
\text {,2762-20 } \\
\text { Andar, } \\
\text { 60740 } \\
\text { FORTALEZA, } \\
\text { Ceará, } \\
\text { Brazil }\end{array}$ & $\begin{array}{l}\text { Curso de } \\
\text { Bibliotecono } \\
\text { mia, } \\
\text { Departament } \\
\text { o de } \\
\text { Communicaç } \\
\text { ao Social e } \\
\text { Bibliotecono } \\
\text { mia, } \\
\text { Centro de } \\
\text { Humanidade } \\
\text { s, } \\
\text { Universidade } \\
\text { Federal do } \\
\text { Ceará, } \\
\text { Avenida de la } \\
\text { Universidade } \\
\text { 2683, } \\
\text { Caixa Postal } \\
719, \\
\text { FORTALEZA, } \\
\text { Ceará } \\
60,000, \\
\text { Brazil }\end{array}$ & $\begin{array}{l}\text { Departament } \\
\text { o de } \\
\text { Bibliotecono } \\
\text { mía, } \\
\text { Faculdade de } \\
\text { Letras, } \\
\text { Universidade } \\
\text { Federal do } \\
\text { Ceará, } \\
\text { Av da } \\
\text { Universidade } \\
2683 \text {, } \\
\text { CP } 819 \text {, } \\
\text { FORTALEZA, } \\
\text { Ceará } 60000 \\
\text { Brazil }\end{array}$ \\
\hline $\begin{array}{l}\text { Faculdade de Comunicação e Biblioteconomía, } \\
\text { Universidade Federal de Goias, } \\
\text { Campus II (Samambaia), } \\
\text { Rodovia Goiânia Nerópolis Km } 12 \\
\text { Prédio da Reitoria } \\
\text { Caixa Postal: } 131 \\
\text { GOIANIA } \\
\text { Goiás CEP:74001-970 - } \\
\text { Brasil } \\
\text { URL: http://www.facomb.ufg.br/page.php } \\
\text { Email: facomb@facomb.ufg.br }\end{array}$ & $x$ & $x$ & $x$ \\
\hline
\end{tabular}




\begin{tabular}{|c|c|c|c|}
\hline $\begin{array}{l}\text { Curso de Licenciatura em Biblioteconomía } \\
\text { Departamento de Pedagogia } \\
\text { Universidade Regional do Noroeste do Estado do } \\
\text { Rio Grande do Sul } \\
\text { Rua São Francisco, } 501 \\
\text { Bairro São Geraldo } \\
\text { IJUÎ } \\
\text { Rio Grande do Sul CEP: } 98700-000 \\
\text { Brasil } \\
\text { URL: http://www.unijui.edu.br } \\
\text { Email: paginas@unijui.tche.br } \\
\text { CANNOT TRACE CURRENT WEB PAGE FOR THIS } \\
\text { COURSE }\end{array}$ & $x$ & $x$ & $x$ \\
\hline $\begin{array}{l}\text { Departamento de Biblioteconomía } \\
\text { Centro de Ciências Sociais Aplicadas } \\
\text { Universidade Federal da Paraíba } \\
\text { Campus I - Castelo Branco } \\
\text { JOÃO PESSOA } \\
\text { Paraíba CEP 58051-900 } \\
\text { Brasil } \\
\text { URL: http://www.prg.ufpb.br/ } \\
\text { Email: cgb@ccsa.ufpb.br }\end{array}$ & $x$ & $\begin{array}{l}\text { Departament } \\
\text { o de } \\
\text { Bibliotecono } \\
\text { mía e } \\
\text { Documentaç } \\
\text { ao, } \\
\text { Centro de } \\
\text { Ciências } \\
\text { Sociais } \\
\text { Aplicadas, } \\
\text { Universidade } \\
\text { Federal da } \\
\text { Paraíba, } \\
\text { Campus } \\
\text { Universitário } \\
\text { I, } \\
58,000 \text { JOAO } \\
\text { PESSOA, } \\
\text { Paraiba } \\
\text { Brazil }\end{array}$ & $\begin{array}{l}\text { Curso de } \\
\text { Bibliotecono } \\
\text { mía, } \\
\text { Instituto } \\
\text { Central de } \\
\text { Filosofía e } \\
\text { Ciěncias } \\
\text { Humanas, } \\
\text { Universidade } \\
\text { Federal da } \\
\text { Paraíba, } \\
\text { JOÃO } \\
\text { PESSOA, } \\
\text { Paraíba } \\
\text { Brazil }\end{array}$ \\
\hline $\begin{array}{l}\text { Departamento de Ciencia da Informacao } \\
\text { Universidade Estadual de Londrina } \\
\text { Campus Universitario } \\
\text { Caixa Postal } 6003 \\
\text { LONDRINA, } \\
\text { Parana CEP 86051-990 } \\
\text { Brasil } \\
\text { URL: http://www.uel.br/ceca/cinf/ } \\
\text { Email: cinf@uel.br }\end{array}$ & $\begin{array}{l}\text { Departament } \\
\text { o de } \\
\text { Bibliotecono } \\
\text { mia, } \\
\text { Centro de } \\
\text { Educacão, } \\
\text { Communicac } \\
\text { ão e Artes, } \\
\text { Universidade } \\
\text { Estadual de } \\
\text { Londrina, } \\
\text { Caixa Postal } \\
6001, \\
\text { Campus } \\
\text { Universitário, } \\
\text { LoNDRINA, } \\
\text { Parana } \\
\text { 86051, } \\
\text { Brasil } \\
\end{array}$ & $\begin{array}{l}\text { Curso de } \\
\text { Bibliotecono } \\
\text { mia, } \\
\text { Centro de } \\
\text { Educaço, } \\
\text { Comunicaço } \\
\text { e Artes, } \\
\text { Fundacao } \\
\text { Universidade } \\
\text { Estadual de } \\
\text { Londrina, } \\
\text { Caixa Postal } \\
2111-\text { CEP } \\
86 \text { 10, } \\
\text { LONDRINA, } \\
\text { Paraná } \\
\text { Brazil }\end{array}$ & $x$ \\
\hline
\end{tabular}




\begin{tabular}{|c|c|c|c|}
\hline $\begin{array}{l}\text { Curso de Biblioteconomía } \\
\text { Faculdades Integradas Teresa D'Ávila - FATEA } \\
\text { Av Peixoto de Castro, } 539 \\
\text { Vila Celeste } \\
\text { Caixa Postal } 75 \\
\text { LORENA } \\
\text { Sao Paolo CEP } 12606-580 \\
\text { Brasil } \\
\text { URL: } \\
\text { http://www.fatea.br/padrao.php?table=graduacao } \\
\text { \&type=2\&id=1 } \\
\text { Email: secretaria-fatea@fatea.br }\end{array}$ & $x$ & $\begin{array}{l}\text { Faculdade de } \\
\text { Bibliotecono } \\
\text { mia e } \\
\text { Documentac } \\
\text { o, } \\
\text { or aculdades } \\
\text { Teresa } \\
\text { d'Avila, } \\
\text { Avenida } \\
\text { Peixoto de } \\
\text { Castro } 539, \\
\text { Caixa Postal } \\
186, \\
\text { LORENA } \\
\text { Sao Paulo } \\
126,000, \\
\text { Brazil }\end{array}$ & $x$ \\
\hline $\begin{array}{l}\text { Curso Pos-graduacao en Biblioteconomía, } \\
\text { Pró-Reitoria de Pós-Graduação e Pesquisa } \\
\text { Universidade Federal de Alagoas } \\
\text { Campus Universitário AC Simões } \\
\text { BR } 104 \text { Norte, Km } 97 \\
\text { Tabuleiro dos Martins } \\
\text { MACEIÓ } \\
\text { Alagoas CEP: } 57072-970 \\
\text { Brasil } \\
\text { URL: } \\
\text { https://sites2.ufal.br/prograd/academico/cursos/ci } \\
\text { eninformacao } \\
\text { Email: biblioteconomia@decos.ufal.br }\end{array}$ & $x$ & $x$ & $x$ \\
\hline $\begin{array}{l}\text { Departamento de Biblioteconomía } \\
\text { Instituto de Ciencias Humanas e Letras } \\
\text { Universidade de Amazonas } \\
\text { Campus Universitario, Aleixo } \\
\text { Av Gal Rodrigo Octavio Jordao Ramos, } 3000 \\
\text { MANAUS } \\
\text { Amazonas CEP 69077-000 } \\
\text { Brasil } \\
\text { URL: } \\
\text { http://www.proeg.ufam.edu.br/cursobibliotecono } \\
\text { mia.htm } \\
\text { Email: biblioteconomia@fua.br }\end{array}$ & $x$ & $\begin{array}{l}\text { Curso de } \\
\text { Bibliotecono } \\
\text { mía, } \\
\text { Instituto de } \\
\text { Ciencias } \\
\text { Humanas e } \\
\text { Letras, } \\
\text { Fundaçao } \\
\text { Universidade } \\
\text { do } \\
\text { Amazonas, } \\
\text { Rua Emílio } \\
\text { Moreira } 601, \\
\text { Caixa Postal } \\
\text { 56, 69, } 000 \\
\text { MANAUS, } \\
\text { Amazonas, } \\
\text { Brazil }\end{array}$ & $x$ \\
\hline
\end{tabular}




\begin{tabular}{|c|c|c|c|}
\hline $\begin{array}{l}\text { Departamento de Ciencia da Informacao } \\
\text { Faculdade de Filosofía e Ciencias } \\
\text { Universidade Estadual de Paulista 'Júlio de } \\
\text { Mesquita Filho' } \\
\text { Campus Universitario } \\
\text { Av Hygino Muzzi Filho } 737 \\
\text { MARILIA } \\
\text { Sao Paolo CEP } 17525 \\
\text { Brasil } \\
\text { URL: } \\
\text { http://www.marilia.unesp.br/ensino/graduacao/bi } \\
\text { blioteconomia.htm } \\
\text { Email: dci@marilia.unesp.br }\end{array}$ & $\begin{array}{l}\text { Departament } \\
\text { o de } \\
\text { Bibliotecono } \\
\text { mía e } \\
\text { Documentac } \\
\text { ao, } \\
\text { Faculdade de } \\
\text { Educacao, } \\
\text { Filosofía, } \\
\text { Ciencias } \\
\text { Sociais e da } \\
\text { Documentac } \\
\text { ao, } \\
\text { Universidade } \\
\text { Estadual de } \\
\text { Paulista, } \\
\text { Campus } \\
\text { Universitario, } \\
\text { Av Hygino } \\
\text { Muzzi Filho } \\
\text { 737, } \\
\text { 17525 } \\
\text { MARILIA SP } \\
\text { Brasil }\end{array}$ & $\begin{array}{l}\text { Curso de } \\
\text { Bibliotecono } \\
\text { mia, } \\
\text { Faculdade de } \\
\text { Educacao, } \\
\text { Filofía, } \\
\text { Ciencias } \\
\text { Socias e da } \\
\text { Documentac } \\
\text { ao, } \\
\text { Universidade } \\
\text { Estadual de } \\
\text { Paulista } \\
\text { "Juílio de } \\
\text { Mesquita } \\
\text { Filho", } \\
\text { Campus de } \\
\text { Marília, } \\
\text { Avenida } \\
\text { Hygino Muzzi } \\
\text { Filho 737, } \\
\text { Caixa Postal } \\
\text { 420 175000, } \\
\text { MARILIA, } \\
\text { Sao Paulo, } \\
\text { Brazil }\end{array}$ & \\
\hline $\begin{array}{l}\text { Curso de Biblioteconomia, } \\
\text { Instituto de Ensino Superior, } \\
\text { Fundaçao de Ensino de Mococa, } \\
\text { Praça Madre Cabrini } 87 \\
\text { MOCOCA, } \\
\text { Sao Paulo } 13,730, \\
\text { Brazil } \\
\text { URL: http://www.fafem.com.br/index.htm } \\
\text { Email: } \\
\text { CANNOT TRACE CURRENT WEB PAGE FOR THIS } \\
\text { COURSE }\end{array}$ & & $\begin{array}{l}\text { Curso de } \\
\text { Bibliotecono } \\
\text { mia, } \\
\text { Instituto de } \\
\text { Ensino } \\
\text { Superior, } \\
\text { Fundaçao de } \\
\text { Ensino de } \\
\text { Mococa, } \\
\text { Praça Madre } \\
\text { Cabrini } 87 \\
\text { MOCOCA, } \\
\text { Sao Paulo } \\
13,730, \\
\text { Brazil }\end{array}$ & \\
\hline
\end{tabular}

\begin{tabular}{|l|l|l|l|}
\hline Departamento de Biblioteconomía & & \\
Centro de Ciências Sociais Aplicadas, & & \\
Universidade Federal do Rio Grande do Norte, & & \\
Campus Universitário Lagoa Nova - BR 101 & $\mathrm{x}$ & \\
Avenida Senador Salgado Filho, 3000 & & \\
Caixa Postal 1524 & & \\
NATAL & & \\
Rio Grande do Norte CEP 59072-970 & & \\
Brasil & & \\
URL: & & \\
http://sol.ccsa.ufrn.br/ccsa/areas/biblio/biblioteco & & \\
nomia/ & & \\
Email: cobi@ccsa.ufrn.br & & \\
\hline
\end{tabular}




\begin{tabular}{|c|c|c|c|}
\hline $\begin{array}{l}\text { IBICT/UFF Programa de Pós Graduação em Ciência } \\
\text { da Informação } \\
\text { Departamento de Ciencia da Informacao } \\
\text { Instituto de Arte e Comunicação Social } \\
\text { Universidade Federal Fluminense } \\
\text { Rua Lara Vilela, } 126 \\
\text { São Domingos } \\
\text { NITERÓI } \\
\text { Rio de Janeiro CEP 24210-590 } \\
\text { Brasil } \\
\text { URL: http://www.uff.br/cienciainformacao/ } \\
\quad \text { http://www.uff.br/ppgci/ } \\
\text { Email: gdodoct@vm.uff.br }\end{array}$ & $X$ & $\begin{array}{l}\text { Curso de } \\
\text { Bibliotecono } \\
\text { mía e } \\
\text { Documentaç } \\
\text { ão, } \\
\text { Departament } \\
\text { o de } \\
\text { Documentaç } \\
\text { ão, } \\
\text { Instituto de } \\
\text { Arte e } \\
\text { Comunicação } \\
\text { Social, } \\
\text { Universidade } \\
\text { Federal } \\
\text { Fluminense, } \\
\text { Rua Lara } \\
\text { Vilela 126, } \\
\text { NITERÓI, } \\
\text { Rio de } \\
\text { Janeiro } \\
\text { 24,000 } \\
\text { Brazil }\end{array}$ & $x$ \\
\hline
\end{tabular}

\begin{tabular}{|c|c|c|c|}
\hline $\begin{array}{l}\text { Departamento de Ciências da Informação } \\
\text { Facultade de Biblioteconomía e Comunicacao } \\
\text { Universidade Federal do Rio Grande do Sul } \\
\text { Rua Ramiro Barcelos, } 2705 \text { - Santana } \\
\text { PORTO ALEGRE } \\
\text { Rio Grande do Sul CEP 90035-007 } \\
\text { Brasil } \\
\text { URL: } \\
\text { http://www1.ufrgs.br/graduacao/xInformacoesAca } \\
\text { demicas/habilitacoes.php?CodCurso=304\&CodHabi } \\
\text { litacao=51\&sem=2006022 } \\
\text { Email: iara.neves@ufrgs.br }\end{array}$ & $\begin{array}{l}\text { Facultade de } \\
\text { Bibliotecono } \\
\text { mía e } \\
\text { Comunicacao } \\
\text { Úniversidade } \\
\text { Federal do } \\
\text { Rio Grande } \\
\text { do Sul, } \\
\text { PORTO } \\
\text { ALEGRE, } \\
\text { Rio Grande } \\
\text { do Sul CEP } \\
\text { 90046, } \\
\text { Brazil }\end{array}$ & $\begin{array}{l}\text { Facultade de } \\
\text { Bibliotecono } \\
\text { mía e } \\
\text { Comunicacao } \\
\text { Universidade } \\
\text { Federal do } \\
\text { Rio Grande } \\
\text { do Sul, } \\
\text { Rua Jacinto } \\
\text { Gomes } 540, \\
\text { PORTO } \\
\text { ALEGRE, } \\
\text { Rio Grande } \\
\text { do Sul } \\
90,000 \\
\text { Brazil }\end{array}$ & $\begin{array}{l}\text { Facultade de } \\
\text { Bibliotecono } \\
\text { mía e } \\
\text { Comunicacao } \\
\text { Úniversidade } \\
\text { Federal do } \\
\text { Rio Grande } \\
\text { do Sul, } \\
\text { Avenida João } \\
\text { Pessoa 52, } \\
\text { CP 2394, } \\
\text { PORTO } \\
\text { ALEGRE, } \\
\text { RGS } \\
\text { Brazil }\end{array}$ \\
\hline $\begin{array}{l}\text { Departamento de Ciência da Informação } \\
\text { Centro de Artes e Communicao } \\
\text { Universidade Federal do Pernambuco } \\
\text { Av. dos Reitores, s/n } \\
\text { Cidade Universitario } \\
\text { RECIFE } \\
\text { Pernambuco CEP } 50670 \\
\text { Brasil } \\
\text { URL: http://www.ufpe.br/ } \\
\text { Email: dci@npd.ufpe.br }\end{array}$ & $\begin{array}{l}\text { Departament } \\
\text { o de } \\
\text { Bibliotecono } \\
\text { mía, } \\
\text { Centro de } \\
\text { Artes e } \\
\text { Communicao } \\
\text { Úniversidade } \\
\text { Federal do } \\
\text { Pernambuco, } \\
\text { Cidade } \\
\text { Universitario, } \\
\text { RECIFE, } \\
\text { Pernambuco } \\
\text { 50739, } \\
\text { Brazil }\end{array}$ & $\begin{array}{l}\text { Departament } \\
\text { o de } \\
\text { Bibliotecono } \\
\text { mía, } \\
\text { Centro de } \\
\text { Artes e } \\
\text { Communicao } \\
\text { 'Universidade } \\
\text { Federal do } \\
\text { Pernambuco, } \\
\text { Cidade } \\
\text { Universitario, } \\
\text { RECIFE, } \\
\text { Pernambuco } \\
\text { 50,000, } \\
\text { Brazil }\end{array}$ & $x$ \\
\hline
\end{tabular}




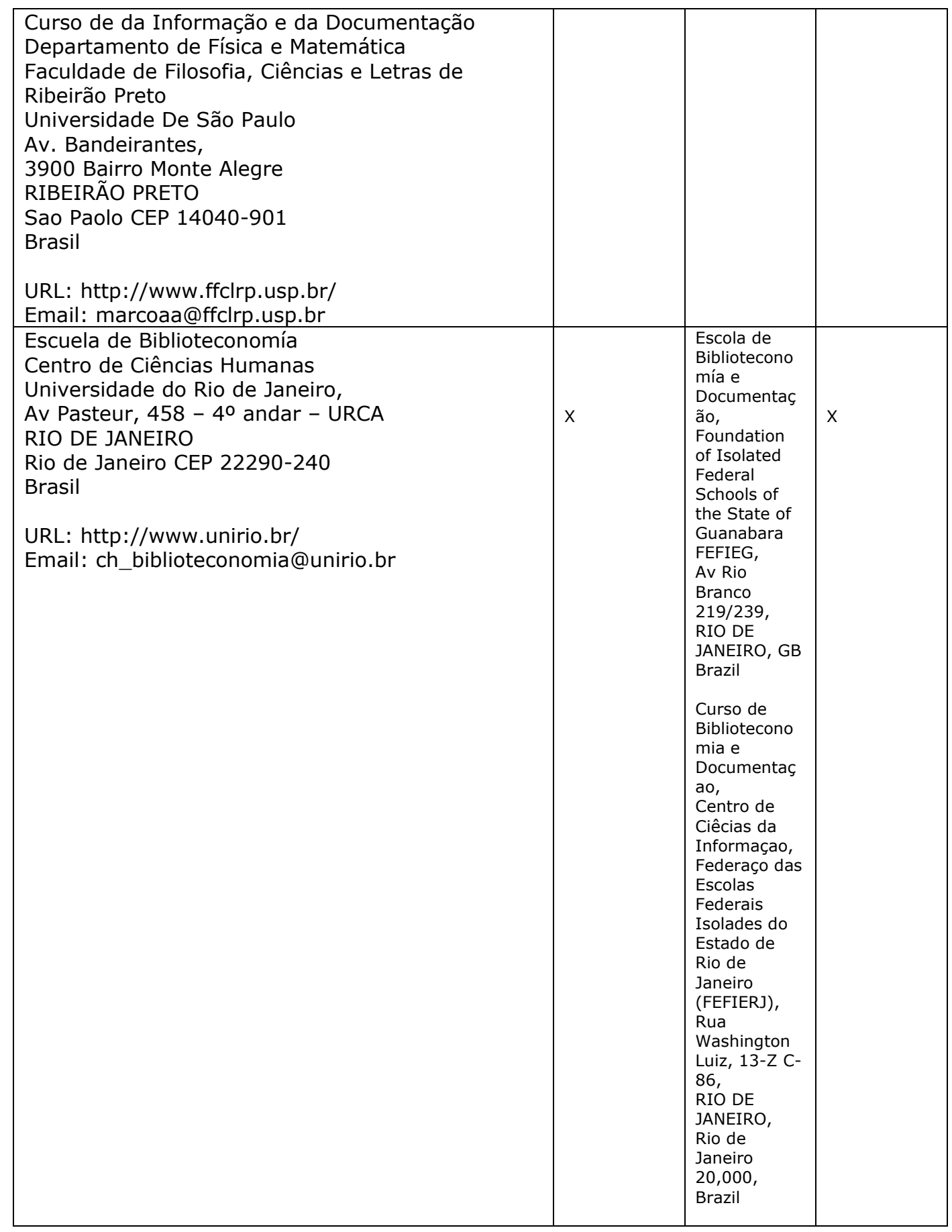




\begin{tabular}{|c|c|c|c|}
\hline $\begin{array}{l}\text { FGV Online - EAD Bibliodata } \\
\text { Fundação Getulio Vargas } \\
\text { Praia de Botafogo, } \\
190 \text { - } 14^{\circ} \text { andar } \\
\text { Botafogo } \\
\text { RIO DE JANEIRO } \\
\text { Rio de Janeiro CEP: } 22250-900 \\
\text { Brasil } \\
\text { URL: http://www.fgv.br/principal/idx_principal.asp } \\
\text { Email: } \\
\text { CANNOT TRACE CURRENT WEB PAGE FOR THIS } \\
\text { COURSE }\end{array}$ & $x$ & $x$ & $x$ \\
\hline $\begin{array}{l}\text { Curso de Biblioteconomia } \\
\text { Instituto de Tecnologia da Informação e da } \\
\text { Comunicação, } \\
\text { Universidade Santa Ursula } \\
\text { Rua Fernando Ferrari } 75 \\
\text { Botafogo } \\
\text { RIO DE JANEIRO } \\
\text { Rio de Janeiro CEP 22231-040 } \\
\text { Brasil } \\
\text { URL: } \\
\text { http://www.usu.br/itic/graduacao/biblio/default.ht } \\
\text { m } \\
\text { Email: iticdir@ax.apc.org }\end{array}$ & $\begin{array}{l}\text { Departament } \\
\text { o de } \\
\text { Bibliotecono } \\
\text { mia e } \\
\text { Documentaç } \\
\text { ão } \\
\text { de Ciência da } \\
\text { Informação, } \\
\text { Centro de } \\
\text { Documentaç } \\
\text { ão e Letras, } \\
\text { Universidade } \\
\text { Santa Ursula } \\
\text { Rua } \\
\text { Fernando } \\
\text { Ferrari } 75 \\
\text { Botafogo } \\
\text { RIO DE } \\
\text { JANEIRO - } \\
\text { RJ CEP } \\
\text { 22231 } \\
\text { Brasil }\end{array}$ & $\begin{array}{l}\text { Departament } \\
\text { o de Ciêcia } \\
\text { da } \\
\text { Informaço, } \\
\text { Universidade } \\
\text { de Santa } \\
\text { Ursula, } \\
\text { Rua } \\
\text { Fernando } \\
\text { Ferrari 75, } \\
\text { Botafogo, } \\
\text { RIO DE } \\
\text { JANEIRO } \\
\text { Brazil }\end{array}$ & \begin{tabular}{|l|} 
Escola de \\
Bibliotecono \\
mía e \\
Documentaç \\
ão, \\
Faculdade de \\
Bibliotecono \\
mía e \\
Documentaç \\
ão, \\
Associação \\
Universitária \\
Santa Ursúla, \\
Rua Farani \\
75, \\
RIO DE \\
JANEIRO, GB \\
Brazil
\end{tabular} \\
\hline
\end{tabular}

\begin{tabular}{|c|c|c|}
\hline $\begin{array}{l}\text { Programa de Pós Graduação em Ciência da } \\
\text { Informação } \\
\text { Instituto Brasileiro de Informação em Ciência e } \\
\text { Tecnologia (IBICT) } \\
\text { Rua Lauro Muller, } 455,50 \text { andar, } \\
\text { no bairro de Botafogo, } \\
\text { RIO DE JANEIRO, } \\
\text { Rio de Janeiro } \\
\text { Brasil } \\
\text { URL: http://www.ibict.br/secao.php?cat=Pós- } \\
\text { Graduação\%20em\%20CI } \\
\text { Email: }\end{array}$ & $\begin{array}{l}\text { Curso de } \\
\text { Pos- } \\
\text { Graduaçao } \\
\text { em Cências } \\
\text { da } \\
\text { Informaçao, } \\
\text { Instituto } \\
\text { Brasileiro de } \\
\text { Informaço } \\
\text { em Ciência e } \\
\text { Technologia, } \\
\text { Rua General } \\
\text { Argola 90, } \\
\text { Sao } \\
\text { Cristovao, } \\
\text { RIO DE } \\
\text { JANEIRO, } \\
\text { Rio de } \\
\text { Janeiro } \\
20,940, \\
\text { Brazil }\end{array}$ & $\begin{array}{l}\text { Cursos } \\
\text { especializado } \\
\text { s e de pós } \\
\text { graduação, } \\
\text { Instituto } \\
\text { Brasileiro de } \\
\text { Bibliografía e } \\
\text { Documentaç } \\
\text { ão, } \\
\text { Av General } \\
\text { Justo } 171, \\
\text { RIO DE } \\
\text { JANEIRO, GB } \\
\text { Brazil }\end{array}$ \\
\hline
\end{tabular}




\begin{tabular}{|c|c|c|c|}
\hline $\begin{array}{l}\text { Comissao de Curso de Biblioteconomía, } \\
\text { Departamento de Biblioteconomía e Historia, } \\
\text { Fundacao Universidade Federal do Rio Grande, } \\
\text { Av Italia, Km } 8 \\
\text { Campus Carreiros, } \\
\text { Caixa postal 474, } \\
\text { RIO GRANDE } \\
\text { Rio Grande do Sol CEP } 96201-900 \\
\text { Brasil } \\
\text { URL: http://www.furg.br/furg/gradua/920.html } \\
\text { Email: ccbiblio@super.furg.br }\end{array}$ & $x$ & $\begin{array}{l}\text { Curso de } \\
\text { Bibliotecono } \\
\text { mía, } \\
\text { Departament } \\
\text { o de } \\
\text { Bibliografía e } \\
\text { Informâtica, } \\
\text { Fundaçao } \\
\text { Universidade } \\
\text { Federal do } \\
\text { Rio Grande, } \\
\text { Rua } \\
\text { Engenheiro } \\
\text { Huch 475, } \\
\text { Caixi Postal } \\
\text { 474, } \\
\text { RIO } \\
\text { GRANDE, } \\
\text { Rio Grande } \\
\text { do Sol } \\
\text { Brazil }\end{array}$ & $x$ \\
\hline $\begin{array}{l}\text { Instituto de Ciência da Informação } \\
\text { Universidade Federal do Bahia } \\
\text { Campus Universitario de Canela } \\
\text { Av Reitor Miguel Calmon, s/n Vale do Canela } \\
\text { SALVADOR } \\
\text { Bahia CEP 40110-100 } \\
\text { Brasil } \\
\text { URL: http://www.ici.ufba.br/ } \\
\text { Email: ici@ufba.br }\end{array}$ & $\begin{array}{l}\text { Escola de } \\
\text { Bibliotecono } \\
\text { mía e } \\
\text { Documentaç } \\
\text { ão, } \\
\text { Universidade } \\
\text { Federal da } \\
\text { Bahia, } \\
\text { Campus } \\
\text { Universitario } \\
\text { do Canela, } \\
\text { SALVADOR, } \\
\text { Bahia 41830- } \\
\text { 200 } \\
\text { Brazil }\end{array}$ & $\begin{array}{l}\text { Escola de } \\
\text { Bibliotecono } \\
\text { mía e } \\
\text { Communicaç } \\
\text { ão, } \\
\text { Universidade } \\
\text { Federal da } \\
\text { Bahia, } \\
\text { Campus } \\
\text { Universitario } \\
\text { de Caneta, } \\
\text { SALVADOR, } \\
\text { Bahia 40,000 } \\
\text { Brazil }\end{array}$ & $\begin{array}{l}\text { Escola de } \\
\text { Bibliotecono } \\
\text { mía e } \\
\text { Communicas } \\
\text { ão, } \\
\text { Vale do } \\
\text { Canela, } \\
\text { Universidade } \\
\text { Federal da } \\
\text { Bahia, } \\
\text { SALVADOR, } \\
\text { Bahia } \\
\text { Brazil }\end{array}$ \\
\hline $\begin{array}{l}\text { Faculdade de Arquivologia, } \\
\text { Centro de Ciências Sociais e Humanas } \\
\text { Universidade Federal de Santa Maria, } \\
\text { Prédio } 353 \text { (Antigo Hospital Universitário), } 30 \\
\text { Andar } \\
\text { SANTA MARIA, } \\
\text { Rio Grande do Sul 97015-370, } \\
\text { Brasil } \\
\text { URL: http://www.ufsm.br/ } \\
\text { Email: arquivologia@ccsh.ufsm.br }\end{array}$ & $\begin{array}{l}\text { Faculdade de } \\
\text { Arquivologia, } \\
\text { Universidade } \\
\text { Federal de } \\
\text { Santa Maria, } \\
\text { Rua Floriano } \\
\text { Peixoto, } \\
1184 \text { s302, } \\
\text { SANTA } \\
\text { MARIA, } \\
\text { Rio Grande } \\
\text { do Sul } \\
\text { 97015-370, } \\
\text { Brazil }\end{array}$ & $\begin{array}{l}\text { Curso de } \\
\text { Arquivologia, } \\
\text { Universidade } \\
\text { Federal de } \\
\text { Santa Maria, } \\
\text { Rua Floriano, } \\
\text { Peixoto } \\
\text { 1184, } \\
\text { SANTA } \\
\text { MARIA, } \\
\text { Rio Grande } \\
\text { do Sul } \\
97,100, \\
\text { Brazil }\end{array}$ & \\
\hline
\end{tabular}




\begin{tabular}{|c|c|c|c|}
\hline $\begin{array}{l}\text { Faculdade de Biblioteconomía } \\
\text { Faculdades Integradas Coração de Jesus } \\
\text { Rua Siqueira Campos, } 483 \text { - Centro } \\
\text { SANTO ANDRÉ } \\
\text { Sao Paolo CEP 09020-240 } \\
\text { Brasil } \\
\text { URL: http://www.fainc.com.br/ } \\
\text { Email: secretaria@fatea.salesianas.com.br }\end{array}$ & $x$ & $\begin{array}{l}\text { Curso de } \\
\text { Bibliotecono } \\
\text { mia, } \\
\text { Faculdades } \\
\text { Integradas } \\
\text { Teresa } \\
\text { d'Avila } \\
\text { (FATEA), } \\
\text { Inspetoria } \\
\text { Santa } \\
\text { Catarina de } \\
\text { Sena, } \\
\text { Rua Siqueira } \\
\text { Camos 483- } \\
\text { Centro, } \\
\text { SANTO } \\
\text { ANDRE, } \\
\text { Sao Paulo } \\
\text { 09,000, } \\
\text { Brazil }\end{array}$ & $x$ \\
\hline $\begin{array}{l}\text { Departamento de Ciencia da Informacao, } \\
\text { Centro de Educação e Ciências Humanas } \\
\text { Universidad Federal de Sao Carlos, } \\
\text { Rodovia Washington Luis, Km 235, } \\
\text { Jardim Guanabara, } \\
\text { Caixa Postal 676, } \\
\text { SAO CARLOS } \\
\text { Sao Paolo CEP } 13565 \text { - } 905 \\
\text { Brasil } \\
\text { URL: http://www.ufscar.br/ dci/index.htm } \\
\text { Email: ccbci@power.ufscar.br }\end{array}$ & $\begin{array}{l}\text { Escola de } \\
\text { Bibliotecono } \\
\text { mia e } \\
\text { Documentaç } \\
\text { ão de São } \\
\text { Carlos, } \\
\text { Universidade } \\
\text { Federal de } \\
\text { São Carlos, } \\
\text { Rua São } \\
\text { Sebastião } \\
2828, \\
\text { SĂO } \\
\text { CARLOS, } \\
\text { São Paulo } \\
13560, \\
\text { Brazil }\end{array}$ & $\begin{array}{l}\text { Escola de } \\
\text { Bibliotecono } \\
\text { mia e } \\
\text { Documentaç } \\
\text { ao, } \\
\text { Fundaçao } \\
\text { Educacional } \\
\text { de Sao } \\
\text { Carlos, } \\
\text { Rua Sao } \\
\text { Sebastiao } \\
2828, \\
\text { Caixa Postal } \\
\text { 382, } \\
\text { SAO PAULO, } \\
\text { Sao Paolo } \\
\text { 13,560, } \\
\text { Brazil }\end{array}$ & $\begin{array}{l}\text { Escola de } \\
\text { Bibliotecono } \\
\text { mía e } \\
\text { Documentą̧ } \\
\text { ão de São } \\
\text { Carlos, } \\
\text { Rua } \\
\text { Episcopal } \\
1253 \text {, } \\
\text { SÃO } \\
\text { CARLOS, } \\
\text { SP } \\
\text { Brazil }\end{array}$ \\
\hline
\end{tabular}

\begin{tabular}{|c|c|c|c|}
\hline $\begin{array}{l}\text { Departamento de Biblioteconomía, } \\
\text { Centro de Ciencias Sociais, } \\
\text { Universidade Federal do Maranhao } \\
\text { Av dos Portugueses s/n, S-D } 307 \\
\text { Campus Universitario do Bacanga, } \\
\text { SAO LUIS } \\
\text { Maranhao CEP 65080-000 } \\
\text { Brasil } \\
\text { URL: } \\
\text { http://www.ufma.br/graduacao/biblioteconomia/in } \\
\text { dex.php } \\
\text { Email: debliot@ufma.br }\end{array}$ & $\begin{array}{l}\text { Universidade } \\
\text { Federal do } \\
\text { Maranhão, } \\
\text { Centro de } \\
\text { Ciencias } \\
\text { Sociais, } \\
\text { Coordinadori } \\
\text { a de Curso } \\
\text { de } \\
\text { Bibliotecono } \\
\text { mía, } \\
\text { Av dos } \\
\text { Portugueses, } \\
\text { Campus } \\
\text { Universitario, } \\
\text { SAO LUIS } \\
\text { Maranhao } \\
65080 \\
\text { Brasil }\end{array}$ & $\begin{array}{l}\text { Curso de } \\
\text { Bibliotecono } \\
\text { mía, } \\
\text { Departament } \\
\text { o de Artes e } \\
\text { Communicaç } \\
\text { ao, } \\
\text { Instituto de } \\
\text { Letras e } \\
\text { Artes, } \\
\text { Universidade } \\
\text { Federal do } \\
\text { Maranhao, } \\
\text { Campus } \\
\text { Universitário } \\
\text { do Bacanga, } \\
\text { SAO LUIS, } \\
\text { Maranhao } \\
65,000 \\
\text { Brasil }\end{array}$ & $\begin{array}{l}\text { Curso de } \\
\text { Bibliotecono } \\
\text { mía, } \\
\text { Instituto de } \\
\text { Artes e } \\
\text { Letras, } \\
\text { Fundação } \\
\text { Universidade } \\
\text { do } \\
\text { Maranhão, } \\
\text { Praça } \\
\text { Gonçalves } \\
\text { Dias } 351 \text { 1, } \\
\text { SÃO LUÍS, } \\
\text { Maranhão } \\
\text { Brazil }\end{array}$ \\
\hline
\end{tabular}




\begin{tabular}{|l|l|l|l|}
\hline Bachelerado em Administracao da Informacao & & \\
Faculdades Integradas Teresa Martín (UNIESP - & & \\
Faculdades Integradas Renascença) & $\mathrm{x}$ & $\mathrm{x}$ \\
Unidade 1 & & \\
Rua Antonieta Leitao $129-156$ & & \\
Freguesia do O, & & \\
SAO PAOLO & & \\
Sao Paolo CEP $0295-160$ & & \\
Brasil & & \\
URL: http://www.fatema.br/fatema/index.htm & & \\
Email: & & \\
CANNOT TRACE CURRENT WEB PAGE FOR THIS & & \\
COURSE
\end{tabular}

\begin{tabular}{|c|c|c|c|}
\hline $\begin{array}{l}\text { Pos-Graduacao em Educacao, Leitura, e Biblioteca } \\
\text { Faculdades Integradas Teresa Martín (UNIESP - } \\
\text { Faculdades Integradas Renascença) } \\
\text { Unidade II, } \\
\text { Rua Cardeal Arcoverde, 1097, } \\
\text { Pinheiros } \\
\text { SAO PAOLO } \\
\text { Sao Paolo } \\
\text { Brasil } \\
\text { URL: http://www.fatema.br/fatema/index.htm } \\
\text { Email: } \\
\text { CANNOT TRACE CURRENT WEB PAGE FOR THIS } \\
\text { COURSE }\end{array}$ & $x$ & $x$ & $x$ \\
\hline $\begin{array}{l}\text { Faculdade de Biblioteconomía e Ciência da } \\
\text { Informação } \\
\text { Fundação Escola de Sociologia e Política de São } \\
\text { Paulo, } \\
\text { Rua Cesário Mota, } 262 \\
\text { Vila Buarque } \\
\text { SÃO PAULO } \\
\text { Sao Paolo CEP 01221-020 } \\
\text { Brasil } \\
\text { URL: http://www.fespsp.com.br/bib.htm } \\
\text { Email: info@fespsp.com.br }\end{array}$ & $x$ & $\begin{array}{l}\text { Escola de } \\
\text { Bibliotecono } \\
\text { mia, } \\
\text { Fundação } \\
\text { Escola de } \\
\text { Sociologia e } \\
\text { Política de } \\
\text { São Paulo, } \\
\text { Rua Carlos } \\
\text { Vicari 124, } \\
\text { SAO PAULO } \\
05,033 \\
\text { Brazil }\end{array}$ & \begin{tabular}{|l} 
Escuela de \\
Bibliotecono \\
mía, \\
Fundação \\
Escola de \\
Sociologia e \\
Política de \\
São Paulo, \\
Rua General \\
Jardim 522, \\
São Paulo, \\
Capital \\
Brazil
\end{tabular} \\
\hline
\end{tabular}




\begin{tabular}{|c|c|c|c|}
\hline $\begin{array}{l}\text { Departamento de Biblioteconomía e } \\
\text { Documentação, } \\
\text { Escola de Comunicação e Artes, } \\
\text { Universidade de São Paulo, } \\
\text { Campus Universitária "Armando de Salles } \\
\text { Oliveira", } \\
\text { Av Prof Lúcio Martins Rodrigues, } 443 \\
\text { Cidade Universitária, } \\
\text { Butante } \\
\text { SÃO PAULO, } \\
\text { Sao Paolo CEP 05508-900 } \\
\text { Brasil } \\
\text { URL: } \\
\text { http://www.eca.usp.br/departam/cbd/cursos/inde } \\
\text { x.htm } \\
\text { Email: eca@edu.usp.br }\end{array}$ & $x$ & $\begin{array}{l}\text { Escola de } \\
\text { Communicac } \\
\text { ao, } \\
\text { Universidade } \\
\text { de Sao } \\
\text { Paulo, } \\
\text { Cidade } \\
\text { Universitária } \\
\text { "Armando de } \\
\text { Salles } \\
\text { Oliveira", } \\
\text { Caixa postal } \\
\text { 8191-05568, } \\
\text { BUTANTAN, } \\
\text { Sao Paulo } \\
\text { Brazil }\end{array}$ & $x$ \\
\hline $\begin{array}{l}\text { Cursos de Ciencia da Informacao } \\
\text { Centro de Ensino Superior Anisio Teixeira, } \\
\text { Av. Desembargador Mário da Silva Nunes, } 1000 \\
\text { Jardim Limoeiro } \\
\text { SERRA } \\
\text { Espirito Santo - CEP 29164-240 } \\
\text { Brazil } \\
\text { URL: } \\
\text { http://www.cesat.br/lercurso.asp?cd_curso=4\&tip } \\
\text { o=GRADUAÇÃO } \\
\text { Email: cesat@cesat.br }\end{array}$ & & & \\
\hline $\begin{array}{l}\text { Curso / Habilitação: Biblioteconomia } \\
\text { Instituto Manchester Paulista de Ensino Superior } \\
\text { Rua da Penha, 620 - Centro } \\
\text { SOROCABA } \\
\text { Sao Paolo - 18010-002 } \\
\text { Brasil } \\
\text { URL: } \\
\text { http://www.imapes.br/site/curso/biblioteconomia. } \\
\text { aspx } \\
\text { e-mail: biblioteca@imapes.br }\end{array}$ & & & \\
\hline
\end{tabular}




\begin{tabular}{|l|l|l|}
\hline Curso de Biblioteconomía & & \\
Instituto de Ciências Organizacionais e & & \\
Administrativas, & $x$ & \\
Universidade Vale do Rio Verde de Três Corações, & $x$ & \\
Av Castelo Branco, 82, & & \\
Chácara das Rosas & & \\
TRÊS CORAÇÕES, & & \\
Minas Gerais CEP 37410-000 & & \\
Brasil & & \\
URL: & & \\
http://www.webescolas.com.br/web_school/?ESCC \\
odigo=5 \\
Email: biblioteconomia@unincor.br & & \\
\hline Curso de Biblioteconomía, & & \\
Faculdade de Filosofía, Ciências e Letras de Ubá, \\
Universidade Presidente Antônio Carlos, \\
Rua Lincoln Rodrigues Costa, 165 \\
Bairro Boa Vista, \\
UBÁ \\
Minas Gerais CEP 36500-000 \\
Brasil \\
URL: http://www.unipac.br/ & & \\
Email: & & \\
CANNOT TRACE CURRENT WEB PAGE FOR THIS & & \\
COURSE & & \\
\end{tabular}

\begin{tabular}{|l|l|l|}
\hline Curso / Habilitação: Biblioteconomia & & \\
Centro Universitário Assunção - UNIFAI & \\
(Faculdades Associadas Ipiranga) & \\
Unidade Vila Mariana & \\
Biblioteca D. Duarte L. e Silva & \\
Rua Afonso Celso, 671/711 & \\
VILA MARIANA & \\
São Paulo - 04119-000 & \\
Brasil & \\
URL: & \\
http://www.unifai.edu.br/internet_cat_curso.asp?c & & \\
od_curso_tipo=1 & & \\
E-mail: bibliotecavilamariana@unifai.edu.br & & \\
\end{tabular}




\begin{tabular}{|c|c|c|c|}
\hline $\begin{array}{l}\text { Departamento de Ciência da Informação } \\
\text { Universidade Federal do Espirito Santo, } \\
\text { Centro de Ciências Jurídicas e Econômicas } \\
\text { Av Fernando Ferrari, s/n, } \\
\text { Campus Universitario de Goiabeiras, } \\
\text { Goiabeiras, } \\
\text { VITORIA, } \\
\text { Espirito Santo CEP 29060-900 } \\
\text { Brasil } \\
\text { URL: http://avc.inf.ufes.br/feiravirtual/controle } \\
\text { Email: biblioteconomia@prograd.ufes.br }\end{array}$ & $\begin{array}{l}\text { Departament } \\
\text { o de } \\
\text { Bibliotecono } \\
\text { mía, } \\
\text { Universidade } \\
\text { Federal do } \\
\text { Espírito } \\
\text { Santo, } \\
\text { Campus } \\
\text { Universitário, } \\
\text { Goiabeiras } \\
\text { VITORIA, } \\
\text { Espírito } \\
\text { Santo } \\
\text { 29060-900, } \\
\text { Brazil }\end{array}$ & $\begin{array}{l}\text { Curso de } \\
\text { Bibliotecono } \\
\text { mía e } \\
\text { Documentaç } \\
\text { ao, } \\
\text { Departament } \\
\text { o de } \\
\text { Administraça } \\
\text { o do Centro } \\
\text { de Ciências } \\
\text { Jurídicas e } \\
\text { Económicas, } \\
\text { Universidade } \\
\text { Federal do } \\
\text { Espírito } \\
\text { Santo, } \\
\text { Campus } \\
\text { Universitário } \\
\text { de } \\
\text { Goiabeiras, } \\
\text { VITORIA, } \\
\text { Espírito } \\
\text { Santo 29,000 } \\
\text { Brazil }\end{array}$ & $x$ \\
\hline $\begin{array}{l}\text { Carrera de Bibliotecología } \\
\text { Universidad Bolivariana } \\
\text { Sede Santiago } \\
\text { Huérfanos } 2917 \\
\text { SANTIAGO } \\
\text { Chile } \\
\text { URL: } \\
\text { http://www.ubolivariana.cl/index.php?id=2205 } \\
\text { Email: admision@ubolivariana.cl }\end{array}$ & $x$ & $x$ & $x$ \\
\hline $\begin{array}{l}\text { Escuela de Bibliotecología } \\
\text { Departamento de Gestión de Información, } \\
\text { Facultad de Administración y Economía } \\
\text { Universidad Tecnológica Metropolitana, } \\
\text { Calle Dr. Hernán Alessandri } 722 \text { - 6. Piso } \\
\text { (Providencia) } \\
\text { Metro Estación Salvador } \\
\text { Casilla 9845, } \\
\text { Correo Central, } \\
\text { SANTIAGO, } \\
\text { Chile } \\
\text { URL: } \\
\text { http://www.utem.cl/deptogestinfo/departamento.h } \\
\text { tm\#direccion } \\
\text { Email: maria.menares@utem.cl }\end{array}$ & $\begin{array}{l}\text { Escuela de } \\
\text { Bibliotecologí } \\
\text { a, } \\
\text { Universidad } \\
\text { Tecnológica } \\
\text { Metropolitan } \\
\text { a, } \\
\text { Avenida José } \\
\text { Pedro } \\
\text { Alessandri } \\
\text { No } 1242, \\
\text { SANTIAGO } \\
\text { Chile }\end{array}$ & $\begin{array}{l}\text { Escuela de } \\
\text { Bibliotecologí } \\
\text { a, } \\
\text { Instituto } \\
\text { Profesional } \\
\text { de Santiago, } \\
177 \text { San } \\
\text { Ignacio } \\
\text { Street, } \\
\text { SANTIAGO } \\
\text { Chile }\end{array}$ & $x$ \\
\hline
\end{tabular}




\begin{tabular}{|c|c|c|c|}
\hline $\begin{array}{l}\text { Escuela de Bibliotecología, } \\
\text { Facultad de Filosofía y Educación, } \\
\text { Universidad de Chile, } \\
\text { José Pedro Alessandri no } 845, \\
\text { SANTIAGO, } \\
\text { Chile } \\
\text { URL: http://www.uchile.cl/ } \\
\text { CANNOT TRACE CURRENT WEB PAGE FOR THIS } \\
\text { COURSE }\end{array}$ & $x$ & $x$ & $\begin{array}{l}\text { Escuela de } \\
\text { Bibliotecologí } \\
\text { a, } \\
\text { Facultad de } \\
\text { Filosofía y } \\
\text { Educación, } \\
\text { Universidad } \\
\text { de Chile, } \\
\text { José Pedro } \\
\text { Alessandri no } \\
845, \\
\text { SANTIAGO, } \\
\text { Chile }\end{array}$ \\
\hline $\begin{array}{l}\text { Curso Técnico Nivel Superior en Bibliotecas y } \\
\text { Centros de Información } \\
\text { Faculted de Humanidades } \\
\text { Universidad La República } \\
\text { Agustinas } 1831 \\
\text { SANTIAGO } \\
\text { Chile } \\
\text { URL: } \\
\text { http://www.ulare.cl/link.cgi/Carreras/Humanidade } \\
\text { s/182?raiz= } \\
\text { Email: contacto@ulare.cl }\end{array}$ & $x$ & $x$ & $x$ \\
\hline
\end{tabular}

\begin{tabular}{|l|l|l|}
\hline Curso de Bibliotecología & & \\
Biblioteca & & \\
Universidad Austral de Chile & & \\
Ciudad Universitaria & & \\
Isla Teja, & & \\
Casilla 39-A, & & \\
VALDIVIA & & \\
Chile & & \\
URL: & & \\
http://www.biblioteca.uach.cl/servicios/capacitacio & & \\
n.htm & & \\
Email: & & \\
NOT CERTAIN TO BE A RELEVANT COURSE & & \\
\hline
\end{tabular}




\begin{tabular}{|c|c|c|c|}
\hline $\begin{array}{l}\text { Escuela de Bibliotecología } \\
\text { Facultad de Humanidades } \\
\text { Universidad de Playa Ancha de Ciencias de la } \\
\text { Educación } \\
\text { Av. Playa Ancha, } 850 \\
\text { Casilla } 34 \text { V } \\
\text { VALPARAÍSO } \\
\text { Chile } \\
\text { URL: http://creal.upa.cl/humanidades/index.html } \\
\text { Email: cvalen@upa.cl }\end{array}$ & $x$ & $x$ & $x$ \\
\hline $\begin{array}{l}\text { Facultad de Sistemas de Información y } \\
\text { Documentación } \\
\text { Universidad de la Salle } \\
\text { Sede Chapinero, Cra. } 5 \text { No. 59A-44 } \\
\text { Edificio Fundadores - Nivel J - Piso } 3 \\
\text { BOGOTA } \\
\text { Colombia } \\
\text { URL: } \\
\text { http://www.lasalle.edu.co/pregrado/ppregrado_sis } \\
\text { t_inf_documentacion.htm } \\
\text { Email: bibliog.@jupiter.lasalle.edu.co }\end{array}$ & $\begin{array}{l}\text { Facultad de } \\
\text { Bibliotecologí } \\
\text { a y } \\
\text { Archivistica, } \\
\text { Universidad } \\
\text { de la Salle, } \\
\text { Carrera } 4 \text { b } \\
\text { No } 59-28 \\
\text { BOGOTA } \\
\text { Colombia }\end{array}$ & $\begin{array}{l}\text { Facultad de } \\
\text { Bibliotecologí } \\
\text { a y } \\
\text { Archivistica, } \\
\text { Universidad } \\
\text { de la Salle, } \\
\text { Calle 11, } \\
\text { No 1-47, } \\
\text { Oficina 518, } \\
\text { Apartado } \\
\text { Aéreo 28368, } \\
\text { BOGOTA } \\
\text { Colombia }\end{array}$ & $\begin{array}{l}\text { Escuela de } \\
\text { Bibliotecários } \\
\text { ' } \\
\text { Documentalis } \\
\text { tas y } \\
\text { Archivístas, } \\
\text { Facultad de } \\
\text { Filosofía y } \\
\text { Letras, } \\
\text { Universidad } \\
\text { Social } \\
\text { Católica de la } \\
\text { Salle, } \\
\text { Calle II, } \\
\text { No } 47, \\
\text { Ap Aéreo } \\
\text { 28638, } \\
\text { BOGOTÁ, DF } \\
\text { Colombia }\end{array}$ \\
\hline $\begin{array}{l}\text { Curso de Bibliotecología, } \\
\text { Biblioteca Luis-Ángel Arango, } \\
\text { Banco de la República, } \\
\text { Apartado Aéreo } 12362 \text {, } \\
\text { BOGOTA } \\
\text { Colombia } \\
\text { CANNOT TRACE CURRENT WEB PAGE FOR THIS } \\
\text { COURSE }\end{array}$ & & $\begin{array}{l}\text { Curso de } \\
\text { Bibliotecologí } \\
\text { a, } \\
\text { Biblioteca } \\
\text { Luis-Ángel } \\
\text { Arango, } \\
\text { Banco de la } \\
\text { República, } \\
\text { Apartado } \\
\text { Aéreo } 2362 \text {, } \\
\text { BOGOTA } \\
\text { Colombia }\end{array}$ & $\begin{array}{l}\text { Curso de } \\
\text { Bibliotecologí } \\
\text { a, } \\
\text { Biblioteca } \\
\text { Luis-Angel } \\
\text { Arango, } \\
\text { Banco de la } \\
\text { República, } \\
\text { Calle II no 4- } \\
144_{\text {I }} \\
\text { Apartado } \\
\text { aéreo no } \\
12362 \text {, } \\
\text { Barrio de la } \\
\text { Candelaria, } \\
\text { BOGOTÁ, DF } \\
\text { Colombia }\end{array}$ \\
\hline $\begin{array}{l}\text { Grupo de Biblioteca y Documentación, } \\
\text { Ministerio de Educación Nacional, } \\
\text { Carrera 8a, } \\
\text { No 6-40, } \\
\text { Apartadó Nacional } 8475, \\
\text { BOGOTÁ, DF } \\
\text { Colombia } \\
\text { CANNOT TRACE CURRENT WEB PAGE FOR THIS } \\
\text { COURSE }\end{array}$ & & & $\begin{array}{l}\text { Grupo de } \\
\text { Biblioteca y } \\
\text { Documentaci } \\
\text { ón, } \\
\text { Ministerio de } \\
\text { Educación } \\
\text { Nacional, } \\
\text { Carrera 8a, } \\
\text { No 6-40, } \\
\text { Apartado } \\
\text { Nacional } \\
\text { 8475, } \\
\text { BOGÓ,́, DF } \\
\text { Colombia }\end{array}$ \\
\hline
\end{tabular}




\begin{tabular}{|c|c|}
\hline $\begin{array}{l}\text { Colegio Universitario del Sagrado Corazón de } \\
\text { Jesus } \\
\text { Valle del Lilí, } \\
\text { Apartado aéreo 2438, } \\
\text { Apartado nacional 834, } \\
\text { CALI } \\
\text { Colombia } \\
\text { URL: } \\
\text { http://www.voluntad.com.co/colegios/cdd0340/ini } \\
\text { cio.html } \\
\text { CANNOT TRACE CURRENT WEB PAGE FOR THIS } \\
\text { COURSE }\end{array}$ & $\begin{array}{l}\text { Colegio } \\
\text { Universitario } \\
\text { del Sagrado } \\
\text { Corazón, } \\
\text { Valle del Lilí, } \\
\text { Apartado } \\
\text { aéreo 2438, } \\
\text { Apartado } \\
\text { nacional 834, } \\
\text { CALI } \\
\text { Colombia }\end{array}$ \\
\hline
\end{tabular}

\begin{tabular}{|c|c|c|c|}
\hline $\begin{array}{l}\text { Escuela Interamericana de Bibliotecología } \\
\text { Universidad de Antioquia } \\
\text { Calle } 67 N^{\circ} 53-108 \text {, bloque } 12 \text { - Of } 336 \\
\text { Aptdo aéreo \#13-07, } \\
\text { MEDELLÍN 1226, } \\
\text { Colombia } \\
\text { URL: http://bibliotecologia.udea.edu.co/ } \\
\text { Email: dbilbiotecologia@arhuaco.udea.edu.co }\end{array}$ & $\begin{array}{l}\text { Escuela } \\
\text { Interamerica } \\
\text { na de } \\
\text { Bibliotecologí } \\
\text { a, } \\
\text { Universidad } \\
\text { de Antioquia, } \\
\text { Ciudad } \\
\text { Universitaria, } \\
\text { Apartado } \\
\text { Aéreo 1307, } \\
\text { MEDELLÍN, } \\
\text { Colombia }\end{array}$ & $\begin{array}{l}\text { Escuela } \\
\text { Interamerica } \\
\text { na de } \\
\text { Bibliotecologí } \\
\text { a, } \\
\text { Universidad } \\
\text { de Antioquia, } \\
\text { Apartado } \\
\text { Aéreo \#13- } \\
\text { 07, } \\
\text { MEDELLÍN, } \\
\text { Colombia }\end{array}$ & $\begin{array}{l}\text { Escuela } \\
\text { Interamerica } \\
\text { na de } \\
\text { Bibliotecologí } \\
\text { a, } \\
\text { Universidad } \\
\text { de Antioquia, } \\
\text { Apartado } \\
\text { aéreo } 1307, \\
\text { Apartado } \\
\text { postal } 2120, \\
\text { MEDELLÍN } \\
\text { Colombia }\end{array}$ \\
\hline $\begin{array}{l}\text { Ciencia de la Información y la Documentación : } \\
\text { Bibliotecología y Archivística } \\
\text { Facultad de Ciencias Humanas, } \\
\text { Universidad del Quindío } \\
\text { Avenida Bolívar Calle } 12 \\
\text { Norte Armenia } \\
\text { QUINDÍO } \\
\text { Colombia } \\
\text { URL: http://www.cienciadelainformacion.edu.co/ } \\
\text { Email: cinfo@uniquindio.edu.co }\end{array}$ & - & $X$ & 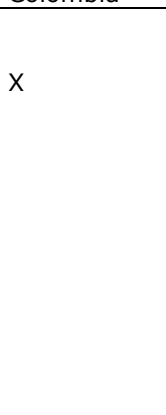 \\
\hline
\end{tabular}




\section{Escuela de Bibliotecología, Documentacion e} Informacion

Facultad de Comunicacion y Lenguaje

Pontificia Universidad Javeriana

Edificio Valtiera

Carrera $7 \mathrm{~N}^{\circ}$ 40-82,

SANTA FE DE BOGOTA, DC

Colombia

URL:

http://www.javeriana.edu.co/Facultades/comunica cion_lenguaje/departamento_informacion.htm

Email: infoydoc@javeriana.edu.co

\begin{tabular}{l|l|l}
$\begin{array}{l}\text { Departament } \\
\text { o de Ciencias } \\
\text { de la }\end{array}$ & $\begin{array}{l}\text { Departament } \\
\text { o de } \\
\text { Bibliotecologí }\end{array}$ & \\
Información & a, & X \\
y & Facultad de & \\
Bibliotecologí & Ciencias \\
a, & Sociales & \\
Facultad de & Carrera, \\
Ciencias & Pontificia & \\
Sociales y & Universidad \\
Educación, & Javeriana, \\
Universidad & Carrera 7 No & \\
Javeriana, & 40-62, \\
Apartado & BOGOTA, DC & \\
aéreo 5315, & Colombia & \\
Carrera 7a & \\
No 40-62, & & \\
BOGOTA, & & \\
Colombia & &
\end{tabular}

Colombia

\begin{tabular}{|c|c|c|c|}
\hline $\begin{array}{l}\text { Escuela de Bibliotecología, Documentación e } \\
\text { Información } \\
\text { Universidad Nacional de Costa Rica } \\
\text { Apartado 86-3000 HEREDIA } \\
\text { Costa Rica } \\
\text { URL: http://www.una.ac.cr/bibliotecologia/ } \\
\text { Email: ebdi@una.ac.cr }\end{array}$ & $\begin{array}{l}\text { Escuela de } \\
\text { Bibliotecologí } \\
\text { a, } \\
\text { Universidad } \\
\text { Nacional, } \\
\text { Apartado 86- } \\
\text { 3000, } \\
\text { HEREDIA } \\
\text { Costa Rica }\end{array}$ & $X$ & $X$ \\
\hline $\begin{array}{l}\text { Escuela de Bibliotecología y Ciencias de la } \\
\text { Información } \\
\text { Universidad de Costa Rica } \\
\text { Ciudad Universitaria Rodrigo Facio } \\
\text { San Pedro de Montes de Oca } \\
\text { SAN JOSÉ } 2060 \\
\text { Costa Rica } \\
\text { URL: http://www.ebci.ucr.ac.cr/ } \\
\text { Email: msandi@ebci.ucr.ac.cr }\end{array}$ & $\begin{array}{l}\text { Escuela de } \\
\text { Bibliotecologí } \\
\text { a y Ciencias } \\
\text { de la } \\
\text { Información, } \\
\text { Facultad de } \\
\text { Educación, } \\
\text { Universidad } \\
\text { de Costa } \\
\text { Rica, } \\
\text { San Pedro de } \\
\text { Montes de } \\
\text { Oca, } \\
\text { Ciudad } \\
\text { Universitaria } \\
\text { Rodrigo } \\
\text { Facio, } \\
\text { SAN JOSÉ } \\
2060 \\
\text { Costa Rica }\end{array}$ & $\begin{array}{l}\text { Departament } \\
\text { o de } \\
\text { Bibliotecologí } \\
\text { a y Ciencias } \\
\text { de la } \\
\text { Información, } \\
\text { Escuela de } \\
\text { Administració } \\
\text { n Educativa, } \\
\text { Facultad de } \\
\text { Educación, } \\
\text { Universidad } \\
\text { de Costa } \\
\text { Rica, } \\
\text { Ciudad } \\
\text { Universitaria } \\
\text { "Rodrigo } \\
\text { Facio", } \\
\text { San Pedro de } \\
\text { Montes de } \\
\text { Oca, } \\
\text { SAN JOSÉ } \\
\text { Costa Rica }\end{array}$ & $\begin{array}{l}\text { Carrera de } \\
\text { Bibliotecologí } \\
\text { a, } \\
\text { Universidad } \\
\text { de Costa } \\
\text { Rica, } \\
\text { Biblioteca, } \\
\text { Ciudad } \\
\text { Universitaria, } \\
\text { SAN JOSÉ } \\
\text { Costa Rica }\end{array}$ \\
\hline
\end{tabular}




\begin{tabular}{|l|l|l|}
\hline Seccion de Archivística & & \\
Escuela de Historia & & \\
Universidad de Costa Rica & & \\
Ciudad Universitaria Rodrigo Facio & & \\
San Pedro de Montes de Oca & & \\
SAN JOSÉ 2060 & & \\
Costa Rica & & \\
URL: & & \\
http://historia.fcs.ucr.ac.cr/archivo/index.html & & \\
Email: admhisto@fcs.ucr.ac.cr & & \\
\hline
\end{tabular}

\begin{tabular}{|c|c|c|c|}
\hline $\begin{array}{l}\text { Centro de Eseňanza e Investigación Tropical, } \\
\text { Instituto Interamericano de Ciencias Agrícolas de } \\
\text { la Organización de Estados Americanos, } \\
\text { TURRIALBA } \\
\text { Costa Rica }\end{array}$ & & & $\begin{array}{l}\text { Centro de } \\
\text { Eseňanza e } \\
\text { Investigación } \\
\text { Tropical, } \\
\text { Instituto } \\
\text { Interamerica } \\
\text { no de } \\
\text { Ciencias } \\
\text { Agrícolas de } \\
\text { la } \\
\text { Organización } \\
\text { de Estados } \\
\text { Americanos, } \\
\text { TURRIALBA } \\
\text { Costa Rica }\end{array}$ \\
\hline $\begin{array}{l}\text { Departamento de Bibliotecología y Ciencia de la } \\
\text { Información } \\
\text { Facultad de Comunicación } \\
\text { Universidad de La Habana } \\
\text { Calle G No } 506 \text { entre } 21 \text { y } 23 \text { Vedado Plaza } \\
\text { CP } 10400 \\
\text { Ciudad de LA HABANA, } \\
\text { Cuba } \\
\text { URL: } \\
\text { http://fcom.uh.cu/departamento_bci/Home.htm } \\
\text { Email: }\end{array}$ & $\begin{array}{l}\text { Facultad de } \\
\text { Comunicació } \\
\text { n, } \\
\text { Científico- } \\
\text { Técnica y } \\
\text { Bibliotecologí } \\
\text { a, } \\
\text { Universidad } \\
\text { de La } \\
\text { Habana, } \\
\text { Street G } \\
506, \\
\text { between } 21 \\
\text { and 23, } \\
\text { Vedado, } \\
\text { HAVANA } \\
\text { Cuba }\end{array}$ & $\begin{array}{l}\text { Departament } \\
\text { o de } \\
\text { Información } \\
\text { Cientifica- } \\
\text { Técnica y } \\
\text { Bibliotecologí } \\
\text { a, } \\
\text { Universidad } \\
\text { de la } \\
\text { Habana, } \\
\text { Zapata y G, } \\
\text { Vedado } \\
\text { Plaza, } \\
\text { Ciudad de LA } \\
\text { HABANA } \\
\text { Cuba }\end{array}$ & $\begin{array}{l}\text { Departament } \\
\text { o de } \\
\text { bibliotecarios } \\
\text { ' } \\
\text { Escuela de } \\
\text { Letras, } \\
\text { Facultad de } \\
\text { Humanidade } \\
\text { s, } \\
\text { Universidad } \\
\text { de la } \\
\text { Habana, } \\
\text { Zapata y G, } \\
\text { Vedado, } \\
\text { LA HABANA } \\
\text { Cuba }\end{array}$ \\
\hline
\end{tabular}




\begin{tabular}{|l|l|l|l|}
\hline Centre of Studies and Professional Development in & & \\
Information Sciences - PROINFO, & $\mathrm{x}$ & $\mathrm{x}$ \\
Capitolio Nacional, & & \\
Industria y San José, & & \\
PO Box 2019, & & \\
LA HABANA 10200, & & \\
Cuba & & \\
URL: http://www.ceniai.inf.cu/proinfo & & \\
Email: & & \\
CANNOT VERIFY THE CURRENT EXISTENCE OF & & \\
THIS COURSE & & \\
\hline
\end{tabular}

\begin{tabular}{|c|c|c|c|}
\hline $\begin{array}{l}\text { Escuela de Auxiliares Técnicos de Biblioteca, } \\
\text { Consejo Nacional de Cultura, } \\
\text { Calle } 2 \text { Esquina a II, } \\
\text { Vedado, } \\
\text { LA HABANA } \\
\text { Cuba } \\
\text { CANNOT TRACE CURRENT WEB PAGE FOR THIS } \\
\text { COURSE }\end{array}$ & & & $\begin{array}{l}\text { Escuela de } \\
\text { Auxiliares } \\
\text { Técnicos de } \\
\text { Biblioteca, } \\
\text { Consejo } \\
\text { Nacional de } \\
\text { Cultura, } \\
\text { Calle 2 } \\
\text { Esquina a II, } \\
\text { Vedado, } \\
\text { LA HABANA } \\
\text { Cuba }\end{array}$ \\
\hline $\begin{array}{l}\text { Centro de Documentación Pedagógica, } \\
\text { Ministerio de Educación, } \\
\text { Obispo y Mercadores, } \\
\text { LA HABANA } \\
\text { Cuba } \\
\text { CANNOT TRACE CURRENT WEB PAGE FOR THIS } \\
\text { COURSE }\end{array}$ & & & $\begin{array}{l}\text { Centro de } \\
\text { Documentaci } \\
\text { ón } \\
\text { Pedagógica, } \\
\text { Ministerio de } \\
\text { Educación, } \\
\text { Obispo y } \\
\text { Mercadores, } \\
\text { LA HABANA } \\
\text { Cuba }\end{array}$ \\
\hline $\begin{array}{l}\text { Escuela de Bibliotecología y Archivología } \\
\text { Universidad de Guayaquil } \\
\text { Facultad de Filosofía y Letras y ciencias de la } \\
\text { Educación } \\
\text { Ciudadela Universitaria } \\
\text { Av. Kennedy y Av. Delta } \\
\text { Casilla } 471 \text { Código Postal 09-01 } \\
\text { GUAYAQUIL } \\
\text { Ecuador } \\
\text { URL: } \\
\text { http://www.ug.edu.ec/facultades/filosofia/index.ht } \\
\text { m } \\
\text { Email: }\end{array}$ & $x$ & $x$ & $x$ \\
\hline
\end{tabular}




\begin{tabular}{|c|c|c|c|}
\hline $\begin{array}{l}\text { Escuela de Bibliotecología } \\
\text { Universidad Católica de Santiago de Guayaquil } \\
\text { Av. Carlos Julio Arosemena Km. } 11 / 2 \\
\text { Apartado postal: 09-01-4671 } \\
\text { GUAYAQUIL } \\
\text { Ecuador } \\
\text { URL: } \\
\text { http://www.ucsg.edu.ec/catolica/index/index_/ind } \\
\text { ex.php } \\
\text { Email: } \\
\text { CANNOT TRACE CURRENT WEB PAGE FOR THIS } \\
\text { COURSE }\end{array}$ & $\begin{array}{l}\text { Escuela de } \\
\text { Bibliotecologí } \\
\text { a } \\
\text { Universidad } \\
\text { Católica de } \\
\text { GUAYAQUIL, } \\
\text { Ecuador }\end{array}$ & & \\
\hline $\begin{array}{l}\text { Curso de Bibliotecología (modalidad de estudios a } \\
\text { distancia) } \\
\text { Universidad Nacional de Loja, } \\
\text { Ciudad Universitaria Guillermo Falconi E, } \\
\text { La Argelia } \\
\text { Casilla Postal: Letra "S" } \\
\text { LOJA, } \\
\text { Ecuador } \\
\text { URL: http://www.unl.edu.ec/ofertamed/oferta- } \\
\text { academica-med.pdf } \\
\text { Email: }\end{array}$ & $\begin{array}{l}\text { Universidad } \\
\text { Nacional de } \\
\text { Loja, } \\
\text { Escuela de } \\
\text { Bibliotecologí } \\
\text { a } \\
\text { LOJA, } \\
\text { Ecuador }\end{array}$ & & \\
\hline $\begin{array}{l}\text { Curso de Restauración y Museología } \\
\text { Facultad de Arquitectura, Artes y Diseño, } \\
\text { Universidad Tecnológica Equinoccial } \\
\text { Campus Matriz Quito } \\
\text { Bourgeois N34-102 y Rumipamba } \\
\text { Casilla Postal: 17-01-2764 } \\
\text { QUITO } \\
\text { Ecuador } \\
\text { URL: http://ute.edu.ec/ } \\
\text { Email: info@ute.edu.ec }\end{array}$ & $x$ & $x$ & $x$ \\
\hline $\begin{array}{l}\text { Carrera de Bibliotecología } \\
\text { Departamento de Letras } \\
\text { Facultad de Ciencias y Humanidades } \\
\text { Universidad de El Salvador } \\
\text { Ciudad Universitaria } \\
\text { Final } 25 \text { Avenida Norte } \\
\text { CP } 1383 \\
\text { SAN SALVADOR } \\
\text { El Salvador } \\
\text { URL: } \\
\text { http://www.ues.edu.sv/academia/sedes_y_faculta } \\
\text { des/Facultades/Ciencias_y_Humanidades.htm\#ofe } \\
\text { rta } \\
\text { Email: }\end{array}$ & $\begin{array}{l}\text { Área de } \\
\text { Bibliotecologí } \\
\text { a, } \\
\text { Departament } \\
\text { o de Letras, } \\
\text { Facultad de } \\
\text { Ciencias y } \\
\text { Humanidade } \\
\text { S, } \\
\text { Universidad } \\
\text { de EI } \\
\text { Salvador, } \\
\text { PO Box } \\
1383, \\
\text { SAN } \\
\text { SALVADOR } \\
\text { EI Salvador }\end{array}$ & $\begin{array}{l}\text { Carrera de } \\
\text { Bibliotecario, } \\
\text { Departament } \\
\text { o de Letras, } \\
\text { Facultad de } \\
\text { Ciencias y } \\
\text { Humanidade } \\
\text { S, } \\
\text { Universidad } \\
\text { de El } \\
\text { Salvador, } \\
\text { Apartado } \\
\text { Postal 143, } \\
\text { SAN } \\
\text { SALVADOR } \\
\text { El Salvador }\end{array}$ & $x$ \\
\hline
\end{tabular}




\begin{tabular}{|c|c|c|c|}
\hline $\begin{array}{l}\text { Escuela de Bibliotecología y Ciencias de la } \\
\text { Información } \\
\text { Universidad Panamericana del El Salvador } \\
\text { Avenida Bernal y Calle el Progreso, } 234 \\
\text { SAN SALVADOR } \\
\text { EI Salvador } \\
\text { URL: http://www.upan.edu.sv/ebaci.html } \\
\text { Email: upebaci@upan.edu.sv }\end{array}$ & $x$ & $x$ & $x$ \\
\hline $\begin{array}{l}\text { Escuela de Bibliotecología } \\
\text { Facultad de Humanidades } \\
\text { Universidad de San Carlos de Guatemala } \\
\text { Ciudad Universitaria Zona } 12 \\
\text { GUATEMALA } \\
\text { Guatemala } 0102 \\
\text { URL: http://www.usac.edu.gt/ } \\
\text { Email: }\end{array}$ & $\begin{array}{l}\text { Escuela de } \\
\text { Bibliotecologí } \\
\text { a, } \\
\text { Facultad de } \\
\text { Humanidade } \\
\text { s, } \\
\text { Universidad } \\
\text { de San } \\
\text { Carlos de } \\
\text { Guatemala, } \\
\text { Ciudad } \\
\text { Universitaria, } \\
\text { Zona 12 } \\
\text { GUATEMALA, } \\
\text { Guatemala }\end{array}$ & $\begin{array}{l}\text { Escuela de } \\
\text { Bibliotecologí } \\
\text { a, } \\
\text { Facultad de } \\
\text { Humanidade } \\
\text { s, } \\
\text { Universidad } \\
\text { de San } \\
\text { Carlos de } \\
\text { Guatemala, } \\
\text { Ciudad } \\
\text { Universitaria, } \\
\text { GUATEMALA, } \\
\text { Guatemala }\end{array}$ & $x$ \\
\hline
\end{tabular}

\begin{tabular}{|l|l|l|}
\hline Maestro en Bibliotecología, & & \\
Departamento de Tecnología Educativa, & \\
Universidad Pedagógica Nacional Francisco & \\
Morazán, & \\
Avenida El Dorado, Boulevard Miraflores & \\
Colonia Las Colinas, & \\
Apartado Postal \# 3394 & \\
TEGUCIGALPA, & \\
Honduras & \\
URL: http://www.upnfm.edu.hn & \\
Email: ncarranza@upnfm.edu.hn & \\
NEW COURSE PROPOSED TO OPERATE FROM & \\
FEBRUARY 2007 WITH FULBRIGHT SUPPORT & \\
\hline Carrera de Bibliotecología & \\
Facultad de Humanidades & \\
Universidad Autónoma de Chiapas, & \\
Calle Canarios y Av. Central s/n & \\
Col. Buenos Aires, Delegación Terán & \\
Colina Universitaria CP 29000 & \\
Campus VI (Tuxtla Gutiérrez) & \\
CHIAPAS & & \\
México & & \\
URL: http://www.humanidades.unach.mx/ & \\
Email: & & \\
\hline
\end{tabular}




\begin{tabular}{|c|c|c|c|}
\hline $\begin{array}{l}\text { Licenciado en Ciencias de la Información, } \\
\text { Facultad de Filosofía y Letras, } \\
\text { Universidad Autónoma de Chihuahua, } \\
\text { Apartado Postal } 744, \\
\text { Rua de las Humanidades s/n, } \\
\text { Ciudad Universitaria, } \\
\text { CHIHUAHUA, } \\
\text { Chihuahua, } \\
\text { México } \\
\text { URL: } \\
\text { http://www.uach.mx/universidad/docs/ffyl.htm } \\
\text { Email: }\end{array}$ & $x$ & $x$ & $x$ \\
\hline $\begin{array}{l}\text { Licenciado en Ciencias de la Información, } \\
\text { Universidad Autónoma de Guadalajara, } \\
\text { Av. Patria } 1201, \\
\text { Lomas del Valle - 3a Sección, } \\
\text { Apartado Postal 1-440, } \\
\text { GUADALAJARA - } 44100 \\
\text { Jalisco } \\
\text { México } \\
\text { URL: http://www.uag.mx/eci/default.htm } \\
\text { Email: eci@uag.mx }\end{array}$ & $x$ & $\begin{array}{l}\text { Escuela de } \\
\text { Bibliotecologí } \\
\text { a, } \\
\text { Facultad de } \\
\text { Filosofía y } \\
\text { Letras, } \\
\text { Universidad } \\
\text { Autónoma de } \\
\text { Guadalajara, } \\
\text { Esquina con } \\
\text { Av. Alcalde, } \\
\text { Apartado } \\
\text { Postal 1-440 } \\
\text { GUADALAJAR } \\
\text { A - 44100 } \\
\text { Jalisco } \\
\text { México }\end{array}$ & $x$ \\
\hline $\begin{array}{l}\text { Departamento de Bibliotecología, } \\
\text { Universidad de Guanajuato } \\
\text { Lascuráin de Retana } 5 \text { - Centro, } \\
\text { GUANAJUATO } \\
\text { Guanajuato 36000, } \\
\text { México } \\
\text { URL: } \\
\text { http://www.ugto.mx/sitioug/espanol/estructurapa } \\
\text { gina/index2.htm } \\
\text { Email: } \\
\text { CANNOT TRACE CURRENT WEB PAGE FOR THIS } \\
\text { COURSE }\end{array}$ & $x$ & $\begin{array}{l}\text { Escuela de } \\
\text { Bibliotecologí } \\
\text { a, } \\
\text { Universidad } \\
\text { de } \\
\text { Guanajuato, } \\
\text { Calle del } \\
\text { Truco \# } 12, \\
\text { GUANAJUAT } \\
\text { O, } \\
\text { Guanajuato, } \\
\text { México }\end{array}$ & $x$ \\
\hline
\end{tabular}




\begin{tabular}{|c|c|c|c|}
\hline $\begin{array}{l}\text { Maestria en Biblioteconomia y Ciencias de } \\
\text { Informacion, } \\
\text { Coordination of Libraries, } \\
\text { Universidad Autonoma de Yucatan, } \\
\text { MERIDA, } \\
\text { Mexico } \\
\text { URL: } \\
\text { http://www.bibliotecas.uady.mx/maestria.html } \\
\text { Email: } \\
\text { COURSE OPERATED IN COLLABORATION WITH } \\
\text { UNAM }\end{array}$ & & & \\
\hline $\begin{array}{l}\text { Departamento de Bibliotecología, } \\
\text { División de Estudios de Postgrado, } \\
\text { Facultad de Filosofía y Letras, } \\
\text { Universidad Nacional Autónoma de México (UNAM) } \\
\text { Ciudad Universitaria, } \\
\text { Delegación Coyoacan } \\
04510 \text { MÉXICO DF } \\
\text { México } \\
\text { URL: } \\
\text { http://www.filos.unam.mx/POSGRADO/programa/ } \\
\text { biblio.htm } \\
\text { Email: }\end{array}$ & $x$ & $x$ & $x$ \\
\hline $\begin{array}{l}\text { Colegio de Bibliotecología, } \\
\text { Facultad de Filosofía y Letras, } \\
\text { Universidad Nacional Autónoma de México } \\
\text { (UNAM), } \\
\text { Ciudad Universitaria, } \\
\text { Delegación Coyoacan, } \\
04510 \text { MÉXICO DF } \\
\text { México } \\
\text { URL: } \\
\text { http://www.dgae.unam.mx/planes/f_filosofia/Bibli } \\
\text { o.pdf } \\
\text { Email: }\end{array}$ & $\begin{array}{l}\text { Colegio de } \\
\text { Bibliotecologí } \\
\text { a } \\
\text { Facultad de } \\
\text { Filosofía y } \\
\text { Letras, } \\
\text { Universidad } \\
\text { Nacional } \\
\text { Autónoma de } \\
\text { Méxiom } \\
\text { (UNAM), } \\
\text { Ciudad } \\
\text { Universitaria, } \\
\text { 04510 } \\
\text { MÉxICO DF } \\
\text { México }\end{array}$ & $\begin{array}{l}\text { Colegio de } \\
\text { Bibliotecologí } \\
\text { a } \\
\text { Facultad de } \\
\text { Filosofía y } \\
\text { Letras, } \\
\text { Universidad } \\
\text { Nacional } \\
\text { Autónoma de } \\
\text { MMexico } \\
\text { (UNAM), } \\
\text { Ciudad } \\
\text { Universitaria, } \\
\text { MÉXICO 20 } \\
\text { DF } \\
\text { México }\end{array}$ & $\begin{array}{l}\text { Colegio de } \\
\text { Bibliotecologí } \\
\text { a y } \\
\text { Archivología, } \\
\text { Facultad de } \\
\text { Filosofía y } \\
\text { Letras, } \\
\text { Universidad } \\
\text { Nacional } \\
\text { Autónoma de } \\
\text { México } \\
\text { (UNAM), } \\
\text { Ciudad } \\
\text { Universitaria, } \\
\text { MÉXICO 20 } \\
\text { DF } \\
\text { México }\end{array}$ \\
\hline
\end{tabular}




\begin{tabular}{|c|c|c|c|}
\hline $\begin{array}{l}\text { Escuela Nacional de Biblioteconomía y } \\
\text { Archivonomia, } \\
\text { Calz Ticoman } 645 \\
\text { Col Srta Ma Ticoman, Delegación Gustavo A } \\
\text { Madero } \\
\text { CP } 07330 \text { MÉXICO, DF } \\
\text { México } \\
\text { URL: http://www.enba.sep.gob.mx/ } \\
\text { Email: bbarajas@sep.gob.mx }\end{array}$ & $\begin{array}{l}\text { Escuela } \\
\text { Nacional de } \\
\text { Bibliotecono } \\
\text { mía y } \\
\text { Archivonomia } \\
\text { '́v. Ticoman } \\
\text { Av. } \\
\text { Col, } \\
\text { Col Sta Ma } \\
\text { Ticoman, } \\
\text { CP 07330 } \\
\text { MÉXICO, DF } \\
\text { México }\end{array}$ & $\begin{array}{l}\text { Escuela } \\
\text { Nacional de } \\
\text { Bibliotecono } \\
\text { mía y } \\
\text { Archivonomía } \\
\text { 'Secretaría de } \\
\text { Educación } \\
\text { Pública, } \\
\text { Viaducto } \\
\text { Miguel } \\
\text { Alemán 155, } \\
\text { MÉXICO, } \\
\text { O3400 } \\
\text { México }\end{array}$ & $\begin{array}{l}\text { Escuela } \\
\text { Nacional de } \\
\text { Bibliotecono } \\
\text { mía y } \\
\text { Archivistas, } \\
\text { Insurgentes } \\
\text { Sur 239, } \\
\text { MÉXICO } 7, \\
\text { DF } \\
\text { México }\end{array}$ \\
\hline $\begin{array}{l}\text { Maestría en Ciencias de la Información y } \\
\text { Administración de Conocimiento, } \\
\text { Instituto Tecnológico y de Estudios Superiores de } \\
\text { Monterrey } \\
\text { Universidad Virtual } \\
\text { MONTERREY } \\
\text { Nuevo León } \\
\text { México } \\
\text { URL: } \\
\text { http://cmportal.itesm.mx/wps/portal/!ut/p/kcxml/ } \\
\text { 04_Sj9SPykssy0xPLMnMzOvMOY_QjzKLN4i3dAHJF } \\
\text { jGpvqRqCKOcAFvfV- } \\
\text { P_NxU_QD9gtzQiHJHRUUA43OWZA!!/delta/base64 } \\
\text { xml/LOIDUOIKQ1RPN29na2tBISEvbOIVUUFBSVFnak } \\
\text { ZJQUFRaENFSVFROEhLz- } \\
\text { RKRmIDbzBlaDFpY29uUVZHaGQtLzdfMF9DTQ!!?W } \\
\text { CM_PORTLET=PC_7_0_CM_WCM\&WCM_GLOBAL_- } \\
\text { CONTEXT=http://cmpubli- } \\
\text { sh.itesm.mx/wps/wcm/connect/ITESM/Aspirantes/ } \\
\text { Maestr\%C3\%ADas/Programas+de+maestr\%C3\% } \\
\text { ADa/Educaci\%C3\%B3n/MIK } \\
\text { Email: }\end{array}$ & $x$ & $x$ & $x$ \\
\hline
\end{tabular}




\begin{tabular}{|c|c|c|c|}
\hline $\begin{array}{l}\text { Cursos en Bibliotecología y Ciencia de la } \\
\text { Informacion } \\
\text { Facultad de Filosofía y Letras } \\
\text { Universidad Autónoma de Nuevo León } \\
\text { Apartado Postal No } 10 \text { - } \\
\text { Sucursal F } \\
\text { Av. Pedro de Alba S/N } \\
\text { Ciudad Universitaria San Nicolás de los Garza } \\
\text { MONTERREY } \\
\text { Nuevo León } 66451 \\
\text { México } \\
\text { URL: } \\
\text { http://www.uanl.mx/oferta/licenciatura/facultades } \\
\text { /ffyl/lic_bibliotecologia.html } \\
\text { Email: }\end{array}$ & $\begin{array}{l}\text { Colegio de } \\
\text { Bibliotecologí } \\
\text { a, } \\
\text { Facultad de } \\
\text { Filosofía y } \\
\text { Letras, } \\
\text { Universidad } \\
\text { Autónoma de } \\
\text { Nuevo León, } \\
\text { Apartado } \\
\text { Postal N }{ }^{\circ} 10 \\
\text { - Sucursal F, } \\
\text { San Nicolás } \\
\text { de los Garza, } \\
\text { MONTERREY, } \\
\text { Nuevo León, } \\
\text { México }\end{array}$ & $\begin{array}{l}\text { Escuela de } \\
\text { Bibliotecologí } \\
\text { a, } \\
\text { Universidad } \\
\text { Autónoma de } \\
\text { Nuevo León, } \\
\text { San Nicolás } \\
\text { de los Garza, } \\
\text { MONTERREY, } \\
\text { Nueva León } \\
64000 \\
\text { México }\end{array}$ & $x$ \\
\hline $\begin{array}{l}\text { Escuela de Bibliotecología e Información } \\
\text { Universidad Autónoma de San Luis Potosí } \\
\text { Av. Industrias, } 101 \\
\text { Fracc Talleres } \\
\text { SAN LUIS POTOSÍ } 78494 \\
\text { México } \\
\text { URL: } \\
\text { http://www.uaslp.mx/Plantilla.aspx?padre=244 } \\
\text { Email: ebi@uaslp.mx }\end{array}$ & $\begin{array}{l}\text { Escuela de } \\
\text { Bibliotecologí } \\
\text { a, } \\
\text { Universidad } \\
\text { Autónoma de } \\
\text { San Luis } \\
\text { Potosí, } \\
\text { SAN LUIS } \\
\text { POTOSÍ } \\
78000 \\
\text { México }\end{array}$ & $x$ & $x$ \\
\hline $\begin{array}{l}\text { Licenciado en Ciencias de la Información } \\
\text { Documental, } \\
\text { Facultad de Humanidades, } \\
\text { Universidad Autónoma del Estado de México, } \\
\text { Av. Universidad Esq Paseo Tollocan Cerro de } \\
\text { Coatepec, CU } \\
\text { CP } 50110 \text { TOLUCA } \\
\text { México } \\
\text { URL: } \\
\text { http://www.uaemex.mx/pestud/licenciaturas/CInf } \\
\text { ormacion.html } \\
\text { Email: fjbc@uaemex.mx }\end{array}$ & $x$ & $x$ & $x$ \\
\hline
\end{tabular}




\begin{tabular}{|c|c|c|c|}
\hline $\begin{array}{l}\text { Universidad Centroamericana. } \\
\text { Avenida Universitaria, } \\
\text { Apartado Postal 69, } \\
\text { MANAGUA, } \\
\text { Nicaragua } \\
\text { URL: http://www.uca.edu.ni/ } \\
\text { CANNOT TRACE CURRENT WEB PAGE FOR THIS } \\
\text { COURSE }\end{array}$ & & & \\
\hline $\begin{array}{l}\text { School of Information Studies, } \\
\text { Florida State University - Panamá } \\
\text { Calle Ernesto J Castillero \#1033 } \\
\text { La Boca, } \\
\text { Balboa - Ancon } \\
\text { PO Box 6-4794 El Dorado } \\
\text { PANAMÁ 6A, } \\
\text { Panamá } \\
\text { URL: http://www.fsu.edu/ cppanama/index.html } \\
\text { Email: }\end{array}$ & $x$ & $x$ & $x$ \\
\hline $\begin{array}{l}\text { Escuela de Bibliotecología } \\
\text { Facultad de Humanidades } \\
\text { Universidad de Panamá, } \\
\text { Juan Díaz Campo Limbergh C45R } \\
\text { Apartado } 10806 \text { Estafeta Universitaria } \\
\text { PANAMÁ CITY } \\
\text { Panamá } \\
\text { URL: } \\
\text { http://www.upanama.up.ac.pa:8080/PortalUp/up.j } \\
\text { sp?submenu=506 } \\
\text { Email: }\end{array}$ & $\begin{array}{l}\text { Departament } \\
\text { o de } \\
\text { Bibliotecologí } \\
\text { a, } \\
\text { Facultad de } \\
\text { Humanidade } \\
\text { s, } \\
\text { Universidad } \\
\text { de Panamá, } \\
\text { Estafeta } \\
\text { Universitaria, } \\
\text { PANAMÁ } \\
\text { Panamá }\end{array}$ & $\begin{array}{l}\text { Escuela de } \\
\text { Bibliotecologí } \\
\text { a, } \\
\text { Departament } \\
\text { o de } \\
\text { Bibliotecologí } \\
\text { a, } \\
\text { Facultad de } \\
\text { Filosofía, } \\
\text { Letras y } \\
\text { Educación, } \\
\text { Universidad } \\
\text { de Panamá, } \\
\text { Estafeta } \\
\text { Universitaria } \\
\text { PANAMÁ } \\
\text { CITY } \\
\text { Panamá }\end{array}$ & $x$ \\
\hline
\end{tabular}

\begin{tabular}{|l|l|l|}
\hline Escuela de Bibliotecologia & & \\
Universidad de Panama, & & \\
Centro Regional Universitario de Veraguas, & & \\
VERAGUAS & & \\
Panama & & \\
URL: & & \\
http://www.upanama.up.ac.pa:8080/PortalUp/up.j & & \\
sp?area=28 & & \\
Email: & & \\
CANNOT TRACE CURRENT WEB PAGE FOR THIS & & \\
COURSE & & \\
\hline
\end{tabular}




\begin{tabular}{|c|c|c|c|}
\hline $\begin{array}{l}\text { Escuela de Bibliotecología } \\
\text { Facultad Politécnica } \\
\text { Universidad Nacional de Asunción } \\
\text { Ciudad Universitaria } \\
\text { Av. San José y 1. de mayo, } 898 \text { - Ruta } 2 \text { - Kim } 14 \\
\text { Bairro San José } \\
\text { Casilla de Correo } 2111 \text { San Lorenzo, } \\
\text { ASUNCIÓN } 1130 \\
\text { Paraguay } \\
\text { URL: } \\
\text { http://www.pol.una.py/paginas/plantilla.php?opc= } \\
\text { licCInfo } \\
\text { Email: }\end{array}$ & $\begin{array}{l}\text { Escuela de } \\
\text { Bibliotecologí } \\
\text { a, } \\
\text { Facultad } \\
\text { Politécnica, } \\
\text { Universidad } \\
\text { Nacional de } \\
\text { Asunción, } \\
\text { Ciudad } \\
\text { Universitaria, } \\
\text { Casilla de } \\
\text { Correo 1408, } \\
\text { San Lorenzo, } \\
\text { ASUNCIÓN } \\
\text { Paraguay }\end{array}$ & $\begin{array}{l}\text { Escuela de } \\
\text { Bibliotecologí } \\
\text { a, } \\
\text { Universidad } \\
\text { Nacional de } \\
\text { Asunción, } \\
\text { Avenida } \\
\text { España } \\
1098, \\
\text { Casilla de } \\
\text { Correo 1408, } \\
\text { ASUNCIÓN } \\
\text { Paraguay }\end{array}$ & $\begin{array}{l}\text { Escuela de } \\
\text { Bibliotecologí } \\
\text { a, } \\
\text { Universidad } \\
\text { Nacional de } \\
\text { Asunción, } \\
\text { Casilla de } \\
\text { Correo 1408, } \\
\text { ASUNCIÓN } \\
\text { Paraguay }\end{array}$ \\
\hline
\end{tabular}

\begin{tabular}{|l|l|l|l|}
\hline Seccion de Bibliotecología y Ciencia de la & & \\
Información & $x$ & $x$ & \\
Departamento de Humanidades & & \\
Facultad de Letras y Ciencias Humanas & & \\
Pontificia Universidad Católica del Perú & \\
Avda Universitaria Cdra 18, San Miguel & \\
Apdo 1761, & & \\
LIMA 100 & & \\
Perú & & \\
URL: & & \\
http://www.pucp.edu.pe/estudios/panelcarrera.ph & & \\
p?rama=012\&espec=2\&etapa=02 & & \\
Email: & & \\
\hline
\end{tabular}




\begin{tabular}{|c|c|c|c|}
\hline $\begin{array}{l}\text { Escuela Académico Profesional de Bibliotecología } \\
\text { y Ciencias de la Información } \\
\text { Facultad de Letras y Ciencias Humanas } \\
\text { Universidad Nacional Mayor de San Marcos } \\
\text { Ciudad Universitaria } \\
\text { Av. Venezuela } 3400 \\
\text { LIMA } 01 \\
\text { Perú } \\
\text { URL: http://www.letras- } \\
\text { unmsm.edu.pe/bibliotecologia.htm } \\
\text { Email: }\end{array}$ & \begin{tabular}{|l} 
Programa de \\
Bibliotecologí \\
a y Ciencias \\
de \\
Información, \\
Universidad \\
Nacional \\
Mayor de \\
San Marcos, \\
Ciudad \\
Universitaria, \\
LIMA \\
Perú
\end{tabular} & $\begin{array}{l}\text { Programa de } \\
\text { Bibliotecologí } \\
\text { a y Ciencias } \\
\text { de } \\
\text { Información } \\
\text { Universidad } \\
\text { Nacional } \\
\text { Mayor de } \\
\text { San Marcos, } \\
\text { Ciudad } \\
\text { Universitaria, } \\
\text { Pabellón de } \\
\text { Letras, } \\
\text { y Av. } \\
\text { Abancay 4a } \\
\text { Cuadra, } \\
\text { Edifició de la } \\
\text { Biblioteca } \\
\text { Nacional, } \\
\text { LIMA } \\
\text { Perú } \\
\text { Escuela } \\
\text { Nacional de } \\
\text { Bibliotecarios } \\
\text { del Perú, } \\
\text { Instituto } \\
\text { Nacional de } \\
\text { Cultura, } \\
\text { Apartado } \\
\text { 2335, } \\
\text { Avenida } \\
\text { Abancy -4A } \\
\text { Cuadra, } \\
\text { LIMA } \\
\text { Perú }\end{array}$ & $\begin{array}{l}\text { Escuela } \\
\text { Nacional de } \\
\text { Bibliotecarios } \\
\text { Biblioteca } \\
\text { Nacional del } \\
\text { Perú, } \\
\text { Apartado } \\
\text { 2335, } \\
\text { Avda Abancy } \\
\text { '4a Cuadra, } \\
\text { LiMA } \\
\text { Perú }\end{array}$ \\
\hline \multicolumn{4}{|l|}{$\begin{array}{l}\text { Escuela Nacional de Archiveros } \\
\text { Archivo General de la Nación } \\
\text { Jr. Rodriguez de Mendoza } 153 \text { - Pueblo libre } \\
\text { (Altura de la } 6 \text { de Bolivar ) } \\
\text { LIMA } \\
\text { Peru } \\
\text { URL: http://agn.perucultural.org.pe/ena.htm } \\
\text { Email: enaagnperu@infonegocio.net.pe }\end{array}$} \\
\hline $\begin{array}{l}\text { Maestria en Ciencias Bibliotecarias y de la } \\
\text { Información } \\
\text { Universidad Interamericana de Puerto Rico } \\
\text { PO Box } 5100 \\
\text { SAN GERMÁN } 00683 \\
\text { Puerto Rico } \\
\text { URL: http://www.inter.edu/oferta/maestrias.asp } \\
\text { Email: }\end{array}$ & $x$ & $x$ & $x$ \\
\hline
\end{tabular}




\begin{tabular}{|c|c|c|c|}
\hline $\begin{array}{l}\text { Escuela Graduada de Bibliotecología y Ciencia de } \\
\text { la Información } \\
\text { Universidad de Puerto Rico } \\
\text { Recinto de Rio Pedras } \\
\text { Edificio Jose M. Lazaro, } 3 \text { piso } \\
\text { Apdo } 21906, \text { Estación UPR } \\
\text { SAN JUAN, 00931-1906 } \\
\text { Puerto Rico } \\
\text { URL: http://egcti.upr.edu/ } \\
\text { Email: egcti@rrpac.upr.clu.edu }\end{array}$ & $\begin{array}{l}\text { Escuela } \\
\text { Graduada de } \\
\text { Bibliotecologí } \\
\text { a y Ciencia } \\
\text { de la } \\
\text { Información, } \\
\text { Universidad } \\
\text { de Puerto } \\
\text { Rico, } \\
\text { BOX 21906, } \\
\text { SAN JUAN } \\
\text { O0931-1906 } \\
\text { Puerto Rico }\end{array}$ & $\begin{array}{l}\text { Escuela } \\
\text { Graduada de } \\
\text { Bibliotecologí } \\
\text { a, } \\
\text { Universidad } \\
\text { de Puerto } \\
\text { Rico, } \\
\text { PO Box } \\
21906, \text { UPR } \\
\text { Station, } \\
\text { Rió Piedras, } \\
\text { SAN JUAN, } \\
\text { O0931 } \\
\text { Puerto Rico }\end{array}$ & $x$ \\
\hline $\begin{array}{l}\text { Maestria en Bibliotecología y Ciencia de la } \\
\text { Información } \\
\text { Instituto Tecnológico de Santo Domingo } \\
\text { Av. Los Próceres - Galá } \\
\text { SANTO DOMINGO } \\
\text { Republica Dominicana } \\
\text { URL: } \\
\text { http://www.intec.edu.do/programas/hum/bci.html } \\
\text { Email: informacion@intec.edu.do }\end{array}$ & $x$ & $x$ & $x$ \\
\hline $\begin{array}{l}\text { Escuela Universitaria de Bibliotecología y Ciencias } \\
\text { Afines Ing. "Federico E Capurro" } \\
\text { Universidad de la Republica Oriental del Uruguay } \\
\text { Emilio Frugoni } 1427 \\
\text { CP } 11200 \\
\text { MONTEVIDEO } \\
\text { Uruguay } \\
\text { URL: http://www.eubca.edu.uy/ } \\
\text { Email: eubca@adinet.com.uy }\end{array}$ & $\begin{array}{l}\text { Escuela } \\
\text { Universitaria } \\
\text { de } \\
\text { Bibliotecologí } \\
\text { a y Ciencias } \\
\text { Afines Ing. } \\
\text { "Federico E } \\
\text { Capurro", } \\
\text { Universidad } \\
\text { de la } \\
\text { Republica, } \\
\text { Tristan } \\
\text { Narvaja } \\
1427, \\
\text { MONTEVIDE } \\
\text { O } \\
\text { Uruguay }\end{array}$ & $\begin{array}{l}\text { Escuela } \\
\text { Universitaria } \\
\text { de } \\
\text { Bibliotecologí } \\
\text { a y Ciencias } \\
\text { Afines Ing. } \\
\text { "Federico E } \\
\text { Capurro", } \\
\text { Tristan } \\
\text { Narvaja } \\
1427 \text {, } \\
\text { MONTEVIDE } \\
\text { O } \\
\text { Uruguay }\end{array}$ & $\begin{array}{l}\text { Escuela } \\
\text { Universitaria } \\
\text { de } \\
\text { Bibliotecologí } \\
\text { a y Ciencias } \\
\text { Universidad } \\
\text { de la } \\
\text { Republica, } \\
\text { Afines, } \\
\text { Colonia } \\
2260, \\
\text { Montevideo } \\
\text { Uruguay }\end{array}$ \\
\hline $\begin{array}{l}\text { Escuela de Bibliotecología y Archivología, } \\
\text { Facultad de Humanidades y Educación, } \\
\text { Universidad Central de Venezuela, } \\
\text { Edificio de la F.H.E. } \\
\text { Ciudad Universitaria } \\
\text { CARACAS, } \\
\text { Venezuela } \\
\text { URL: } \\
\text { http://www.ucv.ve/ftproot/humanidades/FHE2005 } \\
\text { /escuelas/bibliotecologia/index.htm } \\
\text { Email: }\end{array}$ & $\begin{array}{l}\text { Escuela de } \\
\text { Bibliotecologí } \\
\text { a y } \\
\text { Archivología, } \\
\text { Facultad de } \\
\text { Humanidade } \\
\text { s y } \\
\text { Educación, } \\
\text { Universidad } \\
\text { Central de } \\
\text { Venezuela, } \\
\text { Ciudad } \\
\text { Universitaria } \\
\text { CARACAS, } \\
\text { Venezuela }\end{array}$ & $\begin{array}{l}\text { Escuela de } \\
\text { Bibliotecologí } \\
\text { a y } \\
\text { Archivología, } \\
\text { Facultad de } \\
\text { Humanidade } \\
\text { s y } \\
\text { Educación, } \\
\text { Universidad } \\
\text { Central de } \\
\text { Venezuela, } \\
\text { Ciudad } \\
\text { Universitaria } \\
\text { CARACAS, } \\
\text { Venezuela }\end{array}$ & $\begin{array}{l}\text { Escuela de } \\
\text { Bibliotecologí } \\
\text { a y } \\
\text { Archivología, } \\
\text { Facultad de } \\
\text { Humanidade } \\
\text { s y } \\
\text { Educación, } \\
\text { Universidad } \\
\text { Central de } \\
\text { Venezuela, } \\
\text { CARACAS, } \\
\text { Venezuela }\end{array}$ \\
\hline
\end{tabular}




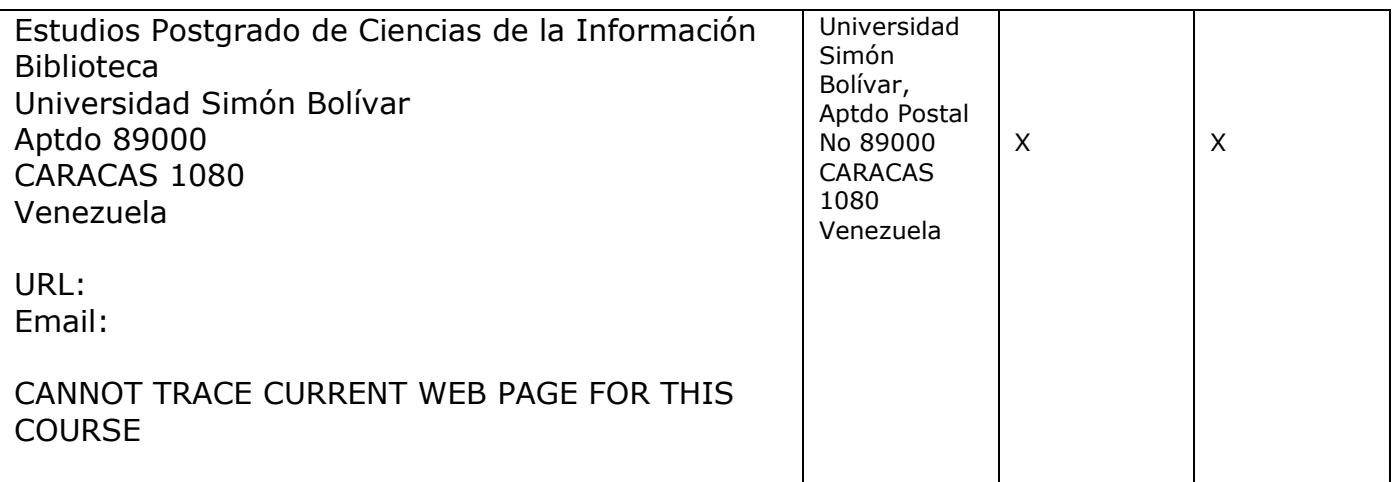

\begin{tabular}{|c|c|c|c|}
\hline $\begin{array}{l}\text { Escuela de Bibliotecologia y Archivologia } \\
\text { Facultad de Humanidades y Educación } \\
\text { Universidad de Zulia } \\
\text { Ciudad Universitaria "Dr. Antonio Borjas Romero" } \\
\text { Núcleo Humanístico } \\
\text { Av. } 16 \text { Goajira } \\
\text { Apartado } 526 \\
\text { MARACAIBO } 410 \\
\text { Estado Zulia } \\
\text { Venezuela } \\
\text { URL: } \\
\text { http://www.luz.edu.ve/Facultades/Humanidades+ } \\
\text { y+Educacion/Facultades+y+N\%C3\%BAcleos+- } \\
\text { +Facultad+de+Humanidades+y+Educacion+- } \\
\text { +Pregrado.htm }\end{array}$ & $\begin{array}{l}\text { Escuela de } \\
\text { Bibliotecologí } \\
\text { a y } \\
\text { Archivología, } \\
\text { Facultad de } \\
\text { Humanidade } \\
\text { s y } \\
\text { Educación, } \\
\text { Universidad } \\
\text { de Zulia, } \\
\text { Apartado } \\
\text { 526, } \\
\text { MARACAIBO } \\
\text { 4011 } \\
\text { Venezuela }\end{array}$ & $\begin{array}{l}\text { Escuela de } \\
\text { Letras } \\
\text { Mención: } \\
\text { Bibliotecologí } \\
\text { a y } \\
\text { Archivología, } \\
\text { Facultad de } \\
\text { Humanidade } \\
\text { s y } \\
\text { Educación, } \\
\text { Universidad } \\
\text { de Zulia, } \\
\text { Ciudad } \\
\text { Universitaria, } \\
\text { Apartado } \\
\text { 526, } \\
\text { MARACAIBO } \\
\text { Venezuela }\end{array}$ & $X$ \\
\hline
\end{tabular}

Information Science Education. Munich, Germany: K.G. Saur. 1985 (IFLA Publication 32)

11 Fang, J.R. Stueart, and Tuamsak, editors. World Guide to Library Archive and Information Science Education. Munich, Germany: K.G. Saur. 1995 (IFLA Publications 72/73)

12 Linares, E., compiler. Guia de escuelas y cursos de bibliotecologia en America Latina. $2^{\text {nd }}$ edition. Washington, D.C., USA: Union Panamericana. 1959

13 Maris Fernandez, S., and Giunti, G.M. Planes de estudio de las escuelas de bibliotecología, archivología y museografía de Iberoamérica. Buenos Aires, Argentina: Sociedad de Investigaciones Bibliotecológicas; IFLA, Progreso de la Bibliotecología en el Tercer Mundo/ALP. 1999 